\title{
Investigating the Potential Use of RADARSAT-2 and UAS imagery for Monitoring the Restoration of Peatlands
}

\author{
Lori White ${ }^{1, *(\mathbb{D}}$, Mark McGovern ${ }^{2}$, Shari Hayne ${ }^{3}$, Ridha Touzi ${ }^{4}$, Jon Pasher ${ }^{1}$ and Jason Duffe ${ }^{1}$ \\ 1 Environment and Climate Change Canada, National Wildlife Research Centre, Ottawa, ON L7S1A1, Canada; \\ Jon.Pasher@canada.ca (J.P.); Jason.Duffe@canada.ca (J.D.) \\ 2 IVUS Geomatics, Ottawa, ON K2C0V3, Canada; markmcgovern57@gmail.com \\ 3 Environment and Climate Change Canada, Science and Technology Branch, Gatineau, QC K1A0H3, Canada; \\ shari.hayne@canada.ca \\ 4 Natural Resources Canada, The Canada Center for Mapping and Earth Observation, Ottawa, ON K1A0E4, \\ Canada; ridha.touzi@canada.ca \\ * Correspondence: Lori.White2@canada.ca
}

Received: 5 June 2020; Accepted: 22 July 2020; Published: 24 July 2020

\begin{abstract}
The restoration of peatlands is critical to help reduce the effects of climate change and further prevent the loss of habitat for many species of flora and fauna. The objective of this research was to evaluate RADARSAT-2 satellite imagery and high-resolution Unmanned Aerial Systems (UASs) to determine if they could be used as surrogates for monitoring the success of peatland restoration. Areas of peatland that were being actively harvested, had been restored from past years (1994-2003), and natural shrub bog in Lac St. Jean, Quebec were used as a test case. We compared the Freeman-Durden and Touzi decompositions by applying the Bhattacharyya Distance (BD) statistic to see if the spectral signatures of restored peatland could be separated from harvested peat and natural shrub bog. We flew Unmanned Aerial Surveys (UASs) over the study site to identify Sphagnum and Polytrichum strictum, two indicator species of early peatland restoration success. Results showed that the Touzi decomposition was better able to separate the spectral signatures of harvested, restored, and natural shrub bog (BD values closer to 9). Symmetric scattering type $\alpha s 1$, Helicity $\left|\tau_{1,2,3}\right|$, a steep incidence angle, and peak growing season appear to be important for separating the spectral signatures. We had moderate success in detecting Sphagnum and Polytrichum strictum visually by using texture and pattern but were unable to use colour due to differences in sun angle and clouds during the UAS flights. Results suggest that RADARSAT-2 data using the Touzi decomposition and UAS imagery show potential for monitoring peatland restoration success over time.
\end{abstract}

Keywords: RADARSAT-2; Unmanned Aerial Systems; peatlands; restoration

\section{Introduction}

\subsection{Peatlands}

Canada has an estimated 123 million hectares of peatlands, which provide a variety of ecosystem services, such as unique habit for a variety of flora and fauna, and water storage, purification and flow control. Additionally, peatlands provide a climate regulation service through the removal of carbon dioxide, and the storage of a large quantity of carbon in the form of deposits of undecomposed peat. The peat deposits found in peatlands may be extracted for a variety of uses such as fuel, chemical absorbents, and, in Canada almost exclusively, as a horticultural product. Canada produces approximately 1.67 million tons [1] of Sphagnum peat moss, most of which are exported abroad. 
Disturbances to peatlands caused by harvesting operations interfere with their hydrology [2] and ability to act as a carbon sink [3], resulting in emissions to the atmosphere of dioxide $\left(\mathrm{CO}_{2}\right)$ and methane $\left(\mathrm{CH}_{4}\right)$, both known greenhouse gases (GHG) [4].

The Canadian peat industry has been working along with academics and government agencies to reduce and mitigate the effects of peat harvesting disturbances for several years. These efforts include developing and implementing field peatland restoration methods for post-harvest sites with the goal of re-establishing a Sphagnum moss cover. Restoration activities include drainage ditch blocking and berm construction to alter the hydrologic regime and the application of Sphagnum seed stock, and applying a mulch cover [5]. These activities can raise the water table, increase the soil pore water pressure, and decrease evapotranspiration [5-7], enabling the Sphagnum seed stock to generate a new moss carpet.

Natural regeneration of vascular and non-vascular plants can occur on bare post-harvest peatlands, and if the correct environmental conditions are present, enable a Sphagnum spp. cover to develop [8]. These environmental conditions include lower $\mathrm{pH}$ levels and a high water table [9]. Polytrichum strictum (referred to subsequently as Polytrichum) is one of the first non-vascular plants to be found on bare peat substrate after a disturbance such as peat harvesting or fire [10]. Polytrichum has been used in some cases as a nurse-plant cover for the establishment of a Sphagnum moss cover with some moderate success $[10,11]$.

In conjunction with the development of peatland restoration techniques, there has been the development of protocols for peatland restoration and tools to evaluate restoration success [12-14]. How effective the peatland restoration was can be gauged by the reappearance of Sphagnum mosses, which can restart a self-regulatory mechanism, and in time re-establish the vegetation and ecosystem characteristics of peatland with the peat accumulation function restored [15]. Ideally, restoration success should be measured quickly (within a few years) after the restoration application has been applied [16] to determine the efficacy of the establishment of Sphagnum moss. These monitoring activities can help determine the site environmental conditions, the extent of Sphagnum cover and the degree of revegetation occurring due to the growth of non-Sphagnum plants. This post-restoration monitoring information can then be used to determine what additional efforts are needed to ensure restoration success [11].

\subsection{Remote Sensing}

Remote sensing has been used to monitor changes in a variety of landscapes, including peatlands [17-20]. Remote sensing is often used because it offers a consistent, large-scale, affordable approach to measuring landscape change. Synthetic aperture radar (SAR) is an active satellite that sends out its own source of energy and measures the returned backscatter. This allows for SAR images to be acquired day or night, in cloudy or hazy conditions [21,22], and to penetrate vegetation cover to varying degrees (depending on the wavelength) [23]. SAR backscatter is affected by the physical characteristics of on the ground targets including surface water, surface roughness, soil moisture, and vegetative biomass [24]. Thus, the backscatter of ground targets will change throughout the year $[25,26]$. The intensity of the SAR backscatter is sensitive to the incidence angle of the emitted wave, and the surface roughness and dielectric properties of the ground features [27]. For example, a smooth surface will return a higher amount of backscatter to the SAR antenna with a steep incidence angle, because as the incidence angle gets shallower, more energy is deflected away from the antenna, resulting in a decrease in backscatter. The opposite is observed for rough surfaces. At steep incidence angles, a rough surface will cause the returned wave to be in multiple directions, resulting in less backscatter being returned to the SAR system compared to smooth surfaces [28]. The dielectric constant of features depends on the type of material the target is composed of and the moisture content. Features with higher moisture content will have a more intense backscatter response compared to drier features [29]. 
Quadrature-polarized SAR systems [30,31] like C-band RADARSAT-2 can transmit and receive energy in all four planes (HH, VV, HV and $\mathrm{VH})$, which allows for the detection of a variety of scattering mechanisms within wetlands [32]. Furthermore, quadrature-polarized SAR satellites can measure the channel phase difference, allowing for the application of polarimetric decompositions. Polarimetric decompositions are commonly used to decompose the received backscatter into different types of scattering mechanisms [33-35].

\subsection{Polarimetric Decompositions}

Two polarimetric decompositions that have previously been used for wetland mapping are the Freeman-Durden (FD) [36-38] and the Touzi decomposition (ICTD) [32,39-43]. The FD, a physically based model, decomposes and estimates the SAR backscatter into a proportion of rough surface, double-bounce and volume scattering within each pixel [44]. Rough surface scattering occurs when objects reflect a single bounce backscatter to the satellite (e.g., rough water or small shrubs); double-bounce scattering results when two smooth features create a right angle, causing the emitted signal to bounce off both features and the majority of the signal is sent back to the SAR system (e.g., emergent vegetation in smooth open water); and volume scattering is observed when the emitted SAR energy is reflected in multiple directions (e.g., vegetation canopies). When no emitted SAR energy is returned to the SAR it is referred to as specular scattering (e.g., smooth open water) [32,39-43].

The Touzi decomposition $[45,46]$ was introduced as an extension of the Kennaugh-Huynen coherent target decomposition (CTD) [47]. The method introduced in 2007 permits the ICTD of partially polarized scattering, as well as the CTD of highly polarized scattering [48]. To extend the Kennaugh-Huynen CTD to the ICTD, the Touzi decomposition relies on the EigenVector Based Decomposition (EVBD) [49]. The coherency matrix [T] decomposition is applied to create a representative of $[T]$ as the incoherent sum of up to three coherence matrices $[T] i$ depicting three different single scatterers (dominant, secondary, tertiary), each weighted by its appropriate positive real eigenvalue $\eta i$, as follows:

$$
[T]=\sum_{i=1,3} \eta_{i}[T]_{i}
$$

A roll-invariant coherent scattering model, the Touzi scattering vector model (TSVM) [45], is used for the parameterization of each coherency eigenvector $\left(k_{i}\right.$ vector presentation of $\left.[T]_{i}\right)$ in terms of terms of four independent parameters, $(\psi, \alpha s, \varphi a s, \tau, \eta)$. The Kennaugh-Huyen maximum polarization orientation angle $(\psi)$ describes the orientation angle of the target scatterer. The scattering type in terms of the polar coordinates ( $\alpha s, \varphi a s)$. The symmetric scattering type magnitude $\alpha s$, which describes the strength and type of radar backscatter. Values of $\alpha$ range from $0-90^{\circ}$, with an $\alpha$ value of $0^{\circ}$ indicating that the backscatter response is surface scattering, $\alpha=45^{\circ}$ represents volume scattering, and $\alpha=90^{\circ}$ denotes double-bounce backscattering. Symmetric Scattering Type Phase $\left(\varphi a s, 0^{\circ}\right.$ to $\left.+/-180^{\circ}\right)$ quantifies the phase offset between odd and even bounce scattering [46]. Phase values that are close to $0^{\circ}$ are representative of surface scattering and values close to $+/-180^{\circ}$ a multiple-scattering interaction such as double-bounce [50]. However, the phase information can only be used under coherent conditions. The Huynen helicity $\tau$ is used for the assessment of the symmetric nature of target scattering. Values of $\tau$ range from $\tau=0^{\circ}-90^{\circ}$, with $\tau=0^{\circ}$ representing a symmetric target and $\tau=45^{\circ}$ an asymmetric target. The representation of the scattering type in terms of the polar coordinates ( $\alpha s, \varphi a s)$, and the helicity $\tau$ permits solving for the Cloude-Pottier scattering type $(\alpha)$ and orientation $(\beta)$ ambiguities raised in [51] and [52], as discussed in [45] and [46]. Finally, the eigenvalues, $\eta_{I}=\left(\lambda_{i} *\left(\operatorname{span}=\eta_{1}+\eta_{2}+\eta_{3}\right)\right)$ [45], represent the optimum intensity for the single scattering $i(i=1,3)$. This corresponds to the proportion of the total power that corresponds to the scattering i. Recently, it was shown the Touzi ICTD is the only eigenvector-based decomposition that leads to a unique decomposition independent of the basis polarization [53]. 


\subsection{Unmanned Aerial Systems}

Unmanned Aerial Systems (UAS) is a relatively new remote sensing technique which has become very popular in the last several years. The advantages of UAS include quick, cost-effective, flexible data collection. UASs allow users to adjust the spatial resolution and spatial extent of the optical imagery collected with each flight. UASs have been used to monitor peatland restoration, and for micro-topography peatland identification and classification [54-57].

\subsection{Research Objectives}

The objective of this research was to evaluate the potential use of RADARSAT-2 C-band SAR data and high-resolution aerial imagery from a UAS as monitoring tools for evaluating the success of post peat harvested peatland restoration activity. To achieve this objective, we:

1. Produced the FD and the ICTD for several RADARSAT-2 images and used the Bhattacharyya Distance (BD) statistic to determine if the spectral signatures from restored peatland (for a variety of years), actively harvested peatland (from three different grades), and natural peatland could be separated.

2. We compared the results from the for Bhattacharyya Distance statistic for RADARSAT-2 images that were acquired at steep and shallow incidence angles to determine if the incidence angle affected the ability to separate spectral signatures of restored, actively harvested, or natural peatland.

3. We used RADARSAT-2 imagery from July, August and October in 2015 to determine if the timing of the growing season affected the ability to differentiate the spectral signatures of restored, actively harvested, and natural shrub peatland.

4. High-resolution UAS imagery was examined to verify if Sphagnum and Polytrichum could be visually identified, providing an early estimate of success for recently restored peatland sites.

\section{Materials and Methods}

\subsection{Study Site}

This research took place at the Sainte-Marguerite-Marie peatland (Figure 1), which is located close to Lac-Saint-Jean in Quebec, Canada $\left(48^{\circ} 47^{\prime} \mathrm{N}, 72^{\circ} 10^{\prime} \mathrm{W}\right)$. Part of this peatland has been harvested by industry for several years. Approximately $40-60 \mathrm{~cm}$ of peat was extracted from most fields before restoration efforts. The Peatland Ecology Research Group from the Université Laval, Quebec has been working in collaboration with the company harvesting and managing the site to apply the moss layer transfer technique. This restoration process involves (1) re-shaping field topography, (2) blocking drainage ditches, (3) in some plots, fertilizing using phosphorus, to encourage the growth of plants that nurse Sphagnum mosses [5,58-60], (4) laying plant diaspores, including Sphagnum mosses extracted from a donor site beforehand, and (5) and scattering straw mulch to shelter diaspores by creating better micro-climatic conditions and avoiding dehydration of plant fragments. 


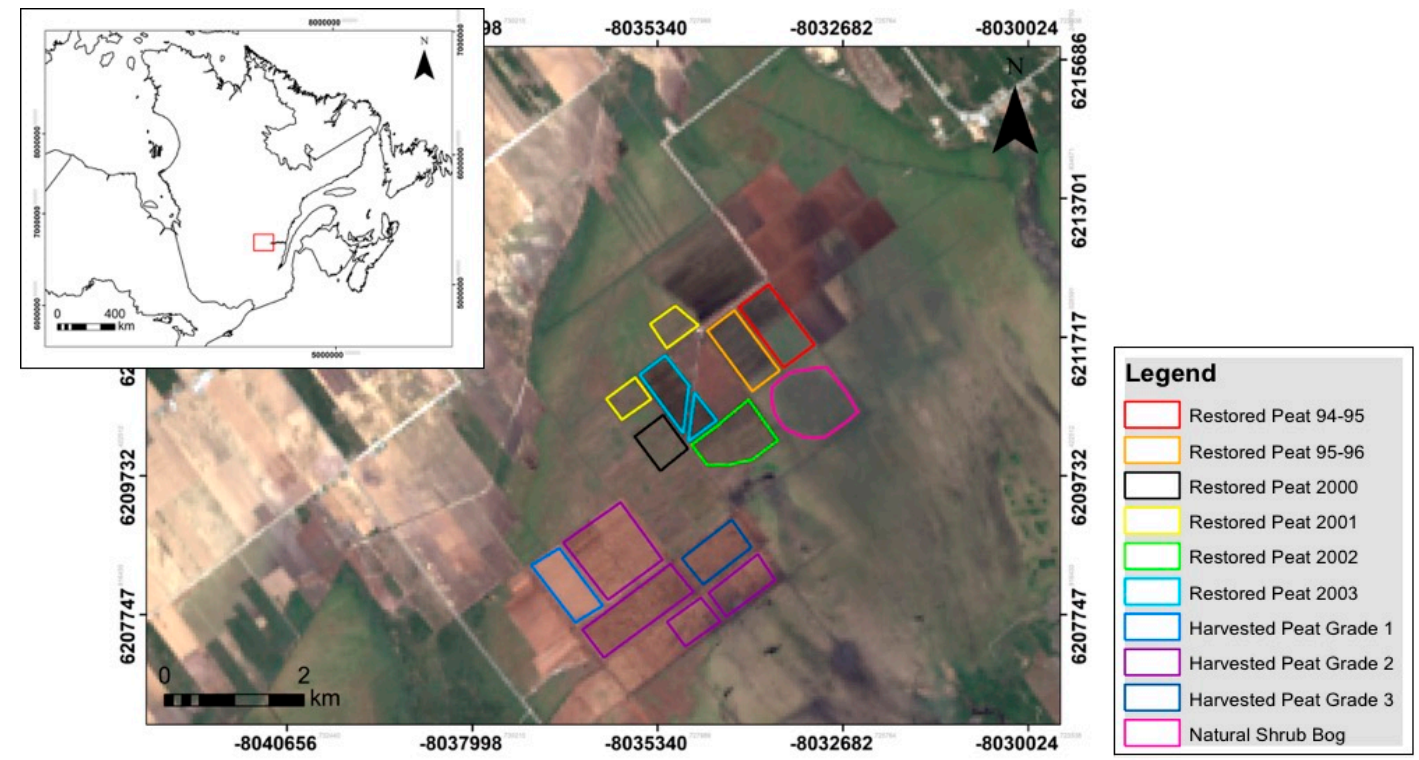

Figure 1. Location map of the Sainte-Marguerite-Marie peatland in Quebec, Canada. The map on the top left shows the location of the Sainte-Marguerite-Marie peatland (red box) in relation to the rest of Quebec, Canada. The lower map shows a close-up view of the Sainte-Marguerite peatland with examples of restored peat from different years, different grades of harvested peat, and natural shrub bog, which were all included in the analysis for this research. The background is a Landsat- 8 image.

\subsection{Satellite Image Processing}

Six RADSARSAT-2 images were acquired in the summer (July and August) and fall (October) of 2015. We wanted to evaluate whether the incidence angle of the SAR image and the timing of the growing season would affect the ability to monitor peatland restoration. To assess these questions, we ordered one steep (FQ4) and one shallow (FQ26) incidence angle RADARSAT-2 image as close together as possible for all three months (Table 1). All RADARSAT-2 images were processed using a model built in PCI Geomatica 2015 (Figure 2). The Touzi ICTD was licensed to PCI Geomatica in the context of the government-industry technology transfer. The PCI Geomatica model imported the raw images as a non-symmetrized scattering matrix (S4C) in Sigma-Naught $\left(\sigma^{\circ}\right)$, then changed to either to a symmetrized covariance matrix (C3RC3) or a symmetrized coherency matrix (T3RC3), which is a requirement for many PCI algorithms. Next, a 5x5 boxcar filter was applied to suppress speckle and increase the effective number of looks. Lastly, the FD and the ICTD decompositions were produced for each image date for both the steep and shallow incidence angles. The target reciprocity assumption is applied in the ICTD, which uses the average of the $\mathrm{HV}$ and $\mathrm{VH}$ magnitude for the cross-polarization magnitude to increase the signal to noise ratio by $3 \mathrm{~dB}[18,61,62]$. It is important to note that a minimum of 80 independent samples was used in the ICTD processing window meeting the requirement for unbiased estimation of the ICTD parameters [63].

Table 1. Description of the RADARSAT-2 images used in this research.

\begin{tabular}{ccccc}
\hline $\begin{array}{c}\text { Beam } \\
\text { Mode }\end{array}$ & Date & $\begin{array}{c}\text { Nominal } \\
\text { Resolution }(\mathbf{m})\end{array}$ & $\begin{array}{c}\text { Nominal Incidence } \\
\text { Angle (degrees) }\end{array}$ & Polarization \\
\hline FQ4 & 15 July 2015 & $13.8-12.7$ & $22.1-24.1$ & $\mathrm{HH}+\mathrm{VV}+\mathrm{HV}+\mathrm{HV}$ \\
FQ4 & 22 August 2015 & $13.8-12.7$ & $22.1-24.1$ & $\mathrm{HH}+\mathrm{VV}+\mathrm{HV}+\mathrm{HV}$ \\
FQ4 & 19 October 2105 & $13.8-12.7$ & $22.1-24.1$ & $\mathrm{HH}+\mathrm{VV}+\mathrm{HV}+\mathrm{HV}$ \\
FQ26 & 18 July 2015 & $7.4-7.3$ & $44.4-45.7$ & $\mathrm{HH}+\mathrm{VV}+\mathrm{HV}+\mathrm{HV}$ \\
FQ26 & 19 August 2015 & $7.4-7.3$ & $44.4-45.7$ & $\mathrm{HH}+\mathrm{VV}+\mathrm{HV}+\mathrm{HV}$ \\
FQ26 & 22 October 2015 & $7.4-7.3$ & $44.4-45.7$ & $\mathrm{HH}+\mathrm{VV}+\mathrm{HV}+\mathrm{HV}$ \\
\hline
\end{tabular}




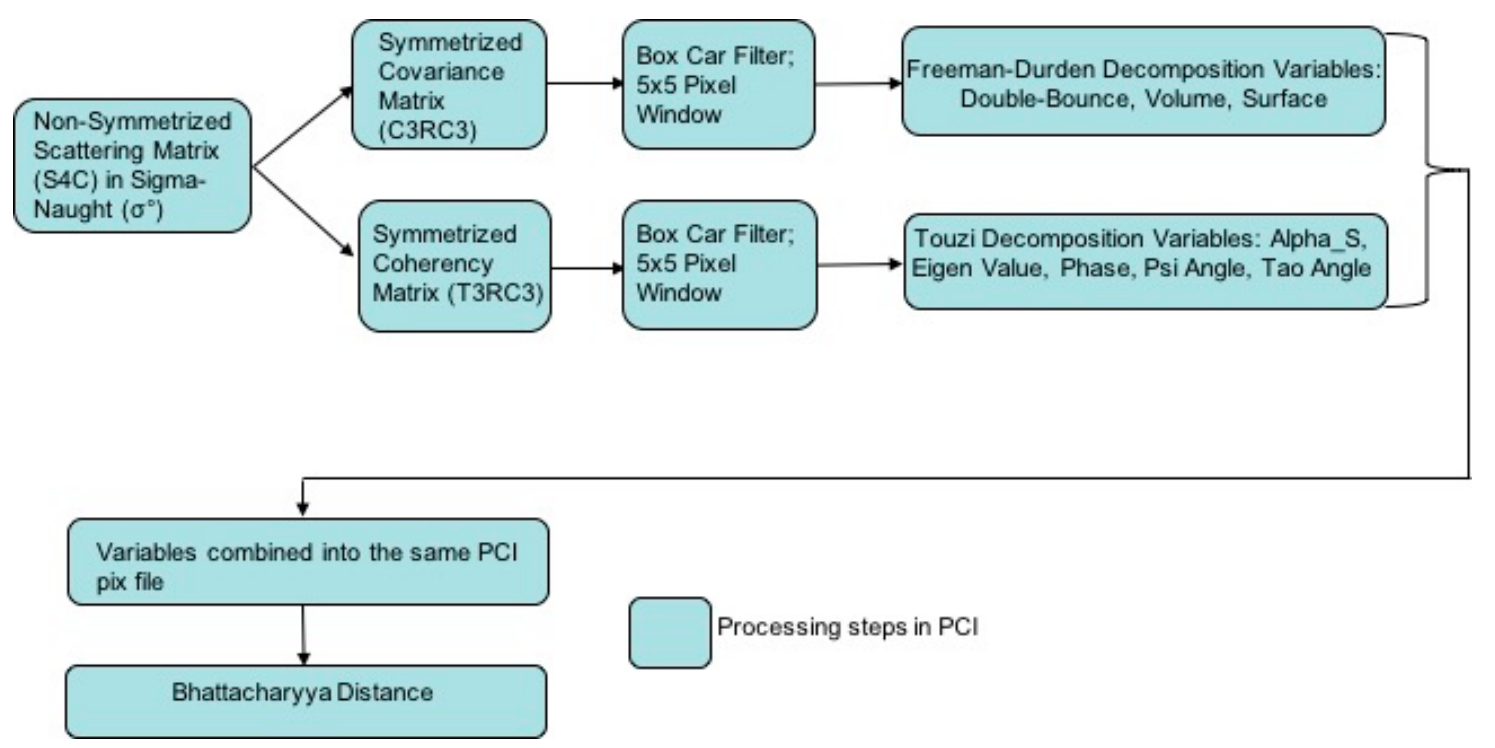

Figure 2. PCI Geomatica Processing chain used to process the FD and the ICTD. The final step was to apply the Bhattacharyya Distance to determine the spectral signature separability between areas of peat that had been restored, peat which is currently being harvested, and natural shrub bog.

We chose to assess both the coherency eigenvectors and the normalized eigenvectors for peatland restoration. The normalized positive real eigenvectors $(\lambda)$ provide a relative measure of energy within the eigenvector, and is calculated as follows:

$$
\lambda_{I}=\eta_{i} / \operatorname{span}(\text { total power) }
$$

To assess the coherence of the phase we calculated the degree of coherence $P_{\Phi \alpha s}$ using the symmetric scattering characterization algorithm. The surface of the symmetric scattering target Poincaré sphere can be used to display all normalized coherent symmetric scatters [46,64]. A point inside the sphere indicates a partially coherent symmetric scatterer and can be calculated with a distance of $P_{\Phi \alpha s}$, also known as the degree of coherence $[30,64,65]$. Values of $P_{\Phi \alpha s}$ range from 0 to 1 , with values $>0.8$ indicating good coherence. $P_{\Phi \alpha}$ is defined as follows [46]:

$$
P_{\Phi \alpha s}=\frac{\sqrt{\left(\left[|a|^{2}-|b|^{2}\right]\right)^{2}+4 \cdot|[a * b]|^{2}}}{\left[|a|^{2}+|b|^{2}\right]}
$$

where $a$ and $b$ are defined from the Pauli components:

$$
\begin{gathered}
a=\frac{(s h h+s v v)}{\sqrt{2}} \\
b=\frac{(s h h-s v v)}{2} * \cos (2 * p s i)-\frac{(s h v-s v h)}{2} * \sin (2 * p s i)
\end{gathered}
$$

One final parameter we included in the ICTD assessment was the Cloude-Pottier anisotropy (A) to determine if the third scattering component was important to separate spectrally restored peat from different years and natural shrub bog. Anisotropy is calculated as $\mathrm{A}=\left(\lambda_{2}-\lambda_{3}\right) /\left(\lambda_{2}+\lambda_{3}\right)$ and measures the amount of mixing between the second and third scattering mechanism. The anisotropy values range from $0-1$, where values equal to 0 indicate that the second and third scattering mechanisms are equally mixed and thus the eigenvalues are equal. Values equal to 1 indicate that the second eigenvalue is much larger than the third [66]. 
Polygon shapefiles were created over locations in Sainte-Marguerite peatland that were actively being harvested, had been restored during different years, and an area of natural shrub bog. Areas of active harvest and natural shrub bog were identified through personal communication with the company harvesting the peat and field data collected in August 2016. Upon visually inspecting the areas of actively harvested peat we noticed a significant spectral difference in areas that have been harvested for many years, compared to areas that had been harvested more recently. Thus, we separated the areas of harvested peat based on grade, with grade 1 representing the areas that were most recently harvested, and grade 3 representing areas that had been harvested for the longest time period. Areas of peat restoration were selected from [11] and personal communication with the peat harvesting company.

The Bhattacharyya Distance (BD) in PCI Geomatica 2015 was used to determine if the spectral signatures of actively harvested peat, restored peat, and natural shrub bog could be statistically separated. A value of 0 indicates the spectral signatures are identical, and a value of 2 indicates the spectral signatures are completely separable [67]. The BD can be used as a measure of the probability of achieving an accurate classification [68], to determine how well land cover classes can be separated, and which parameters have the greatest influence on spectral separability [69].

The UAS surveys took place on 9th and 10th August 2016 at the Sainte-Marguerite-Marie peatland site. The approximately 1100 ha of the site was overflown with a DJI Phantom 3 UAS at three different altitudes (approximately $25 \mathrm{~m}, 40 \mathrm{~m}, 100 \mathrm{~m}$ ) to provide photos at different resolutions. The onboard camera sensing system (Sony EXMOR 1/2.3") was used to take overlapping photos on a regular grid. The total area coverage was broken down into several missions to enable battery changes, data transfer and routine system maintenance. To enable the acquisition of a variety of photos at differing resolutions in a short time available for fieldwork (due to budget constraints) image acquisition took place throughout an entire working day from approximately from early morning to earlier evening. Individual still photos were geotagged using the onboard GPS/GLONASS system.

PIX4D software was used to generate mosaiced image sets based on the geotagged and photo parameter information from each individual photo. A shift on the order of 10-20 m existed in the UAS mosaics from PIX4D. Therefore, to improve the precision, the individual UAS photos for field sampling were georeferenced and rectified.

The processing of the individual UAS photos of interest was done in ESRI ArcMap using a simple nearest-neighbour transformation with ground control points collected from air photos and ArcMap Bing imagery dataset. The resulting rectified UAS images were at resolutions ranging from approximately $2 \mathrm{~cm}$ to approximately $20 \mathrm{~cm}$, depending on which of the original three flight altitudes they were taken at.

For image interpretation purposes, a project was set up in ESRI ArcMap. This project included several ancillary data sources which included imagery (Bing, Landsat, historical aerial photos) and mapping data (field layout and treatment maps, standard topographic 1:50,000 map data). These ancillary data sets were used to provide context and assist in manual image interpretation. The resulting georeferenced UAS photos were visually interpreted to determine visual characteristics of restored areas for the presence of Polytrichum and Sphagnham using ground-based geotagged field photos, field notes and points from [11] as reference points.

\section{Results}

\subsection{Comparison of the Spectral Signatures of Restored Peat and Natural Shrub Bog}

The analysis of the BD (Tables 2-4) values for both the FD and the ICTD demonstrates that the spectral signature of the restored peat became more similar to that of natural shrub bog (BD values closer to 0) the longer since it was restored. The ICTD for the 15 July 2015, and 22 August 2015, FQ4 RADARSAT-2 images was able to completely separate the spectral signatures of peat restored most recently (2003) and natural shrub bog $(\mathrm{BD}=1.9$, Tables 2 and 3). The BD values decreased gradually 
to 0.5 and 0.6 in the 15 July 2015, and 22 August 2015, FQ4 images respectively for peat restored in 1994-1995, indicating the spectral signature was very similar to that of natural shrub bog. This same trend general trend was also observed in the October FQ4 and for the July, August, and October FQ26 RADARSAT-2 images (Tables 2-4). However, in these instances, peat restored in 2003 was not able to be spectrally separated from natural shrub bog (BD values $<1.9$ ). The ICTD had BD values slightly closer to 1.9 compared to the FD for all FQ4 images, as well as the 18 July 2015, FQ26 image. Thus, the type of SAR decomposition, incidence angle, and timing of the growing season are all likely to be affecting the spectral separability of restored peat and natural shrub bog. This research suggests that the ICTD, steep incidence angle and mid to peak growing season are best for the spectral separability of restored peat and natural shrub bog.

The analysis of the FD and ICTD decompositions provides more insight into which parameters are important for separating restored peat and natural shrub bog. The dominant backscatter response in the FD was rough surface scattering in the early years of peatland restoration, accounting for $\sim 81-90 \%$ of the total power in the FQ4 images (Table 5, Figure 3). The $\alpha_{\mathrm{s} 1}$ parameter from the ICTD also shows that the dominant backscatter response was rough surface scattering in the FQ4 images for more recently restored peat ( $\alpha_{\mathrm{s} 1}$ values closer to 0 ), and the $\lambda_{1}$ values indicate that rough surface scattering accounted for $\sim 91-95 \%$ of the total backscatter (Table 6, Figure 4). Both decompositions also demonstrated that over time the magnitude of the rough surface backscatter declined, and the magnitude of the volume scattering increased with increasing time since peat had been restored, becoming more similar to the backscatter response observed in the natural shrub bog area. For example, in the FD the rough surface backscatter response of the July and August FQ4 images for peat restored in 2003 was $\sim 6.5-7$ dB higher compared to natural shrub bog. The difference in rough surface backscatter response declined to 2.5-3.5 dB for peat restored in 1994-1995 in comparison to natural shrub bog (Figure 3). In addition, for peat restored in 1994-1995 the rough surface scattering contribution to total power declined to $\sim 49 \%$, while volume scattering contribution to total power was $\sim 48 \%$ an increase by $\sim 31 \%$ (Table 5).

The same trend was observed in the ICTD FQ4 images. The $\alpha 1$ values for the July and August FQ4 images (Figure 5) increased slightly from $\sim 4.5-5^{\circ}$ for peat restored in 2003 to $\sim 11^{\circ}$ for peat restored in 1994-1995, indicating a slight decrease in rough surface scattering. Additionally, the analysis of $\lambda_{3}$ (Figure $4 \mathrm{D}$ ) shows an increase in $\lambda_{3}(\sim 8-12 \%)$ from indicating an increase in volume scattering. Similarly, when we compared peat restored in 2003 to natural shrub bog the difference in $\lambda_{1}$ was $\sim 11^{\circ}$, but was only $\sim 4.5-5.5^{\circ}$ between peat restored in 1994-1995 and natural shrub bog for the July and August FQ4 images. The $\lambda_{1}$ also declined from $\sim 91 \%$ of total power for peat restored in 2003 to $\sim 76-77 \%$ for peat restored in 1994-1995 (Table 6) for the two FQ4 summer images. The $\lambda_{3}$, which is representative of volume scattering, was $\sim 3 \%$ of the total power for peat restored in 2003 and increased slightly to $\sim 8 \%$ for peat restored in 1994-1995. The trends in $\alpha_{1}, \lambda_{1}$, and $\lambda_{3}$ (rough surface scattering decreasing and volume scattering increasing) is further evidence that the backscatter response of restored peat is becoming more similar to natural shrub bog the longer it is restored (Figure 6). 
Table 2. Bhattacharya distance (BD) statistic for the FQ4 15 July 2015, and FQ26 18 July 2015, RADARSAT-2 images. The BD value indicates whether the spectral responses of natural shrub bog, restored peat, and actively harvested peat can be separated. Values range from 0 to 2.0 . All values equal to or greater than 1.9 indicate good spectral separability.

\begin{tabular}{|c|c|c|c|c|c|c|c|c|c|c|c|c|c|c|c|c|c|c|}
\hline & \multicolumn{2}{|c|}{ Grade 1} & \multicolumn{2}{|c|}{ Grade 2} & \multicolumn{2}{|c|}{ Grade 3} & \multicolumn{2}{|c|}{ Restored 94-95 } & \multicolumn{2}{|c|}{ Restored 95-96 } & \multicolumn{2}{|c|}{ Restored 00} & \multicolumn{2}{|c|}{ Restored 01} & \multicolumn{2}{|c|}{ Restored 02} & \multicolumn{2}{|c|}{ Restored 03} \\
\hline & FD & ICTD & FD & ICTD & FD & ICTD & FD & ICTD & FD & ICTD & FD & ICTD & FD & ICTD & FD & ICTD & FD & ICTD \\
\hline \multicolumn{19}{|c|}{ RADARSAT-2 FQ4 BD 20150715} \\
\hline Grade 2 & 0.3 & 0.5 & & & & & & & & & & & & & & & & \\
\hline Grade 3 & 0.6 & 0.9 & 0.1 & 0.2 & & & & & & & & & & & & & & \\
\hline Restored 94-95 & 1.1 & 1.5 & 1.2 & 1.4 & 1.5 & 1.7 & & & & & & & & & & & & \\
\hline Restored 95-96 & 1.2 & 1.4 & 1.3 & 1.5 & 1.6 & 1.7 & 0.4 & 0.3 & & & & & & & & & & \\
\hline Restored 00 & 1.3 & 1.6 & 1.5 & 1.7 & 1.7 & 1.9 & 0.6 & 0.6 & 0.1 & 0.3 & & & & & & & & \\
\hline Restored 01 & 1.5 & 1.6 & 1.6 & 1.7 & 1.8 & 1.9 & 0.6 & 0.6 & 0.1 & 0.2 & 0.1 & 0.2 & & & & & & \\
\hline Restored 02 & 1.5 & 1.6 & 1.6 & 1.7 & 1.8 & 1.9 & 0.9 & 0.7 & 0.3 & 0.3 & 0.1 & 0.2 & 0.1 & 0.2 & & & & \\
\hline Restored 03 & 1.6 & 1.7 & 1.7 & 1.8 & 1.9 & 1.9 & 1.2 & 1.5 & 0.8 & 1.1 & 0.5 & 0.8 & 0.6 & 0.9 & 0.4 & 0.6 & & \\
\hline Bog & 1.3 & 1.9 & 1.4 & 1.9 & 1.7 & 1.9 & 0.2 & 0.5 & 0.9 & 1.0 & 1.0 & 1.3 & 1.1 & 1.3 & 1.3 & 1.4 & 1.5 & 1.9 \\
\hline \multicolumn{19}{|c|}{ RADARSAT-2 FQ26 BD 20150718} \\
\hline Grade 2 & 0.6 & 0.8 & & & & & & & & & & & & & & & & \\
\hline Grade 3 & 1.8 & 2.0 & 0.6 & 0.8 & & & & & & & & & & & & & & \\
\hline Restored 94-95 & 0.6 & 1.1 & 0.1 & 0.7 & 0.9 & 1.6 & & & & & & & & & & & & \\
\hline Restored 95-96 & 0.3 & 0.8 & 0.1 & 0.6 & 1.2 & 1.6 & 0.1 & 0.2 & & & & & & & & & & \\
\hline Restored 00 & 0.3 & 0.7 & 0.3 & 0.7 & 1.4 & 1.9 & 0.2 & 0.3 & 0.0 & 0.1 & & & & & & & & \\
\hline Restored 01 & 0.2 & 0.9 & 0.3 & 1.0 & 1.5 & 1.9 & 0.2 & 0.3 & 0.0 & 0.2 & 0.0 & 0.2 & & & & & & \\
\hline Restored 02 & 0.1 & 0.5 & 0.3 & 0.7 & 1.5 & 1.8 & 0.3 & 0.4 & 0.1 & 0.1 & 0.1 & 0.2 & 0.0 & 0.2 & & & & \\
\hline Restored 03 & 0.5 & 0.7 & 1.1 & 1.3 & 1.9 & 2.0 & 1.2 & 1.5 & 0.9 & 1.3 & 1.1 & 1.4 & 1.0 & 1.4 & 0.7 & 0.9 & & \\
\hline Bog & 1.1 & 1.6 & 0.3 & 1.2 & 0.8 & 1.7 & 0.1 & 0.2 & 0.4 & 0.6 & 0.5 & 0.7 & 0.6 & 0.6 & 0.7 & 0.9 & 1.6 & 1.8 \\
\hline
\end{tabular}


Table 3. Values represent the Bhattacharya distance (BD) statistic for the RADARSAT-2 FQ4 22 August 2015, and FQ26 19 August 2015 images. This metric was used to determine whether the spectral responses of natural shrub bog, restored peat, and actively harvested peat can be separated. Values equal to or greater than 1.9 indicate good spectral separability and values below 1.9 indicate poor separability.

\begin{tabular}{|c|c|c|c|c|c|c|c|c|c|c|c|c|c|c|c|c|c|c|}
\hline & \multicolumn{2}{|c|}{ Grade 1} & \multicolumn{2}{|c|}{ Grade 2} & \multicolumn{2}{|c|}{ Grade 3} & \multicolumn{2}{|c|}{ Restored 94-95 } & \multicolumn{2}{|c|}{ Restored 95-96 } & \multicolumn{2}{|c|}{ Restored 00} & \multicolumn{2}{|c|}{ Restored 01} & \multicolumn{2}{|c|}{ Restored 02} & \multicolumn{2}{|c|}{ Restored 03} \\
\hline & FD & ICTD & FD & ICTD & FD & ICTD & FD & ICTD & FD & ICTD & FD & ICTD & FD & ICTD & FD & ICTD & FD & ICTD \\
\hline \multicolumn{19}{|c|}{ RADARSAT-2 FQ4 BD 20150822} \\
\hline Grade 2 & 0.4 & 0.5 & & & & & & & & & & & & & & & & \\
\hline Grade 3 & 0.8 & 1.1 & 0.4 & 0.6 & & & & & & & & & & & & & & \\
\hline Restored 94-95 & 1.1 & 1.2 & 1.0 & 1.4 & 1.5 & 1.8 & & & & & & & & & & & & \\
\hline Restored 95-96 & 1.1 & 1.2 & 1.0 & 1.4 & 1.6 & 1.8 & 0.4 & 0.2 & & & & & & & & & & \\
\hline Restored 00 & 1.4 & 1.6 & 1.2 & 1.5 & 1.8 & 2.0 & 0.4 & 0.5 & 0.1 & 0.2 & & & & & & & & \\
\hline Restored 01 & 1.5 & 1.7 & 1.3 & 1.6 & 1.9 & 2.0 & 0.7 & 0.6 & 0.2 & 0.3 & 0.1 & 0.3 & & & & & & \\
\hline Restored 02 & 1.6 & 1.7 & 1.4 & 1.6 & 1.9 & 2.0 & 0.9 & 0.7 & 0.4 & 0.4 & 0.3 & 0.2 & 0.1 & 0.1 & & & & \\
\hline Restored 03 & 1.6 & 1.7 & 1.2 & 1.4 & 1.9 & 1.9 & 1.2 & 1.5 & 0.9 & 1.3 & 0.7 & 1.0 & 0.6 & 1.0 & 0.6 & 0.8 & & \\
\hline Bog & 1.3 & 1.8 & 1.3 & 1.9 & 1.7 & 2.0 & 0.3 & 0.6 & 0.8 & 1.0 & 0.9 & 1.2 & 1.2 & 1.3 & 1.4 & 1.4 & 1.6 & 1.9 \\
\hline \multicolumn{19}{|c|}{ RADARSAT-2 FQ26 BD 20150819} \\
\hline Grade 2 & 0.4 & 0.5 & & & & & & & & & & & & & & & & \\
\hline Grade 3 & 0.6 & 0.8 & 0.2 & 0.3 & & & & & & & & & & & & & & \\
\hline Restored 94-95 & 0.7 & 0.8 & 0.6 & 0.8 & 1.0 & 1.3 & & & & & & & & & & & & \\
\hline Restored 95-96 & 0.6 & 0.8 & 0.6 & 0.9 & 1.1 & 1.5 & 0.1 & 0.1 & & & & & & & & & & \\
\hline Restored 00 & 0.7 & 0.9 & 0.7 & 1.0 & 1.3 & 1.6 & 0.2 & 0.2 & 0.1 & 0.1 & & & & & & & & \\
\hline Restored 01 & 0.8 & 1.1 & 0.8 & 1.1 & 1.4 & 1.7 & 0.1 & 0.2 & 0.0 & 0.1 & 0.1 & 0.2 & & & & & & \\
\hline Restored 02 & 1.0 & 1.3 & 0.9 & 1.1 & 1.5 & 1.8 & 0.4 & 0.3 & 0.2 & 0.2 & 0.1 & 0.2 & 0.2 & 0.2 & & & & \\
\hline Restored 03 & 1.6 & 1.8 & 1.4 & 1.5 & 1.9 & 2.0 & 1.3 & 1.3 & 1.1 & 1.2 & 1.1 & 1.2 & 1.1 & 1.2 & 0.6 & 0.8 & & \\
\hline Bog & 0.8 & 1.0 & 0.8 & 1.1 & 1.0 & 1.3 & 0.2 & 0.2 & 0.5 & 0.4 & 0.7 & 0.6 & 0.6 & 0.5 & 1.1 & 0.9 & 1.8 & 1.8 \\
\hline
\end{tabular}


Table 4. Results of the Bhattacharya distance (BD) statistic comparing the separability of the spectral responses for natural shrub bog, restored peat, and actively harvested using the RADARSAT-2 FQ4 19 October 2015, and FQ26 22 October 2015 images. All values equal to or greater than 1.9 suggest good spectral separability and values below 1.9 suggest poor separability.

\begin{tabular}{|c|c|c|c|c|c|c|c|c|c|c|c|c|c|c|c|c|c|c|}
\hline & \multicolumn{2}{|c|}{ Grade 1} & \multicolumn{2}{|c|}{ Grade 2} & \multicolumn{2}{|c|}{ Grade 3} & \multicolumn{2}{|c|}{ Restored 94-95 } & \multicolumn{2}{|c|}{ Restored 95-96 } & \multicolumn{2}{|c|}{ Restored 00} & \multicolumn{2}{|c|}{ Restored 01} & \multicolumn{2}{|c|}{ Restored 02} & \multicolumn{2}{|c|}{ Restored 03} \\
\hline & FD & ICTD & FD & ICTD & FD & ICTD & FD & ICTD & FD & ICTD & FD & ICTD & FD & ICTD & FD & ICTD & FD & ICTD \\
\hline \multicolumn{19}{|c|}{ RADARSAT-2 FQ4 BD 20151019} \\
\hline Grade 2 & 0.2 & 0.3 & & & & & & & & & & & & & & & & \\
\hline Grade 3 & 0.7 & 0.9 & 0.3 & 0.4 & & & & & & & & & & & & & & \\
\hline Restored 94-95 & 1.3 & 1.4 & 0.8 & 0.9 & 0.3 & 0.4 & & & & & & & & & & & & \\
\hline Restored 95-96 & 1.0 & 1.1 & 0.5 & 0.6 & 0.1 & 0.2 & 0.1 & 0.2 & & & & & & & & & & \\
\hline Restored 00 & 1.2 & 1.3 & 0.6 & 0.7 & 0.2 & 0.3 & 0.1 & 0.2 & 0.1 & 0.1 & & & & & & & & \\
\hline Restored 01 & 1.1 & 1.3 & 0.5 & 0.7 & 0.1 & 0.2 & 0.2 & 0.2 & 0.1 & 0.2 & 0.1 & 0.2 & & & & & & \\
\hline Restored 02 & 0.7 & 0.8 & 0.2 & 0.2 & 0.1 & 0.2 & 0.5 & 0.6 & 0.2 & 0.2 & 0.3 & 0.4 & 0.2 & 0.3 & & & & \\
\hline Restored 03 & 0.8 & 1.0 & 0.4 & 0.4 & 0.8 & 0.8 & 1.2 & 1.3 & 0.9 & 1.0 & 1.0 & 1.1 & 0.9 & 1.1 & 0.5 & 0.5 & & \\
\hline Bog & 1.8 & 1.9 & 1.5 & 1.7 & 1.2 & 1.3 & 0.5 & 0.7 & 0.8 & 1.1 & 0.7 & 0.9 & 0.8 & 0.9 & 1.2 & 1.4 & 1.7 & 1.8 \\
\hline \multicolumn{19}{|c|}{ RADARSAT-2 FQ26 BD 20151022} \\
\hline Grade 2 & 0.4 & 0.6 & & & & & & & & & & & & & & & & \\
\hline Grade 3 & 1.5 & 1.8 & 0.5 & 0.6 & & & & & & & & & & & & & & \\
\hline Restored 94-95 & 1.1 & 0.9 & 0.7 & 0.6 & 0.9 & 1.1 & & & & & & & & & & & & \\
\hline Restored 95-96 & 0.6 & 0.9 & 0.2 & 0.4 & 0.7 & 0.9 & 0.3 & 0.2 & & & & & & & & & & \\
\hline Restored 00 & 0.3 & 0.3 & 0.4 & 0.5 & 1.3 & 1.5 & 0.5 & 0.6 & 0.2 & 0.5 & & & & & & & & \\
\hline Restored 01 & 0.5 & 0.5 & 0.5 & 0.5 & 1.2 & 1.4 & 0.3 & 0.3 & 0.1 & 0.3 & 0.1 & 0.2 & & & & & & \\
\hline Restored 02 & 0.2 & 0.4 & 0.5 & 0.6 & 1.4 & 1.5 & 0.8 & 0.5 & 0.4 & 0.5 & 0.2 & 0.1 & 0.3 & 0.1 & & & & \\
\hline Restored 03 & 0.4 & 0.4 & 1.0 & 0.5 & 1.8 & 1.4 & 1.4 & 0.7 & 1.1 & 0.7 & 0.8 & 0.2 & 1.0 & 0.3 & 0.3 & 0.2 & & \\
\hline Bog & 1.6 & 1.7 & 1.2 & 1.4 & 1.2 & 1.6 & 0.3 & 0.6 & 0.9 & 0.8 & 1.2 & 1.4 & 0.9 & 1.0 & 1.4 & 1.2 & 1.8 & 1.5 \\
\hline
\end{tabular}


a

a 0.045

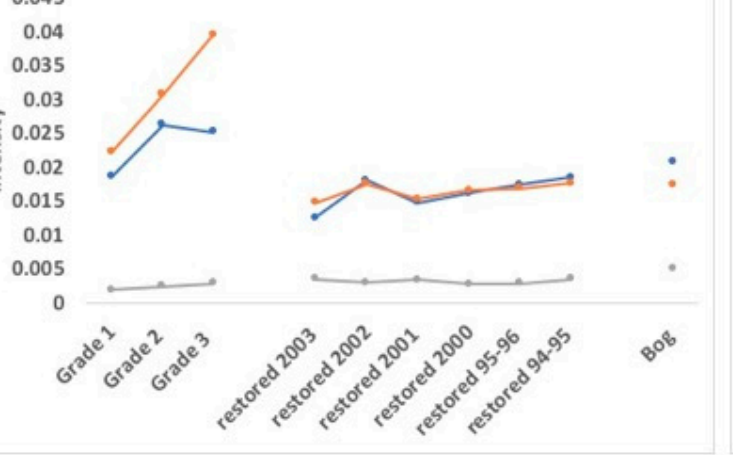

b

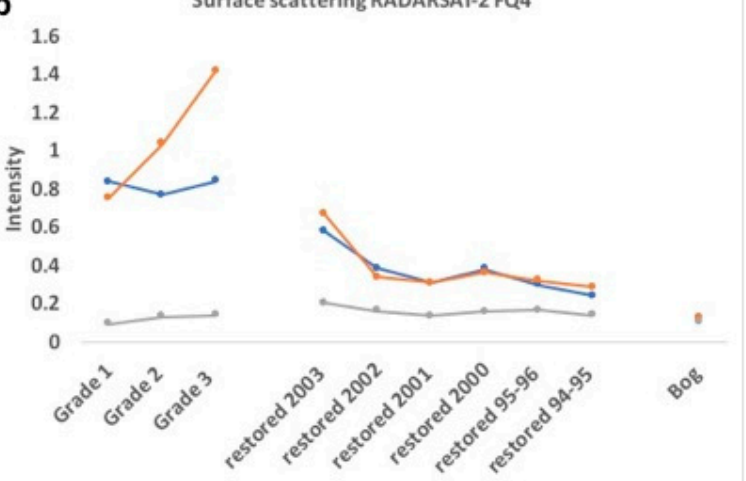

c

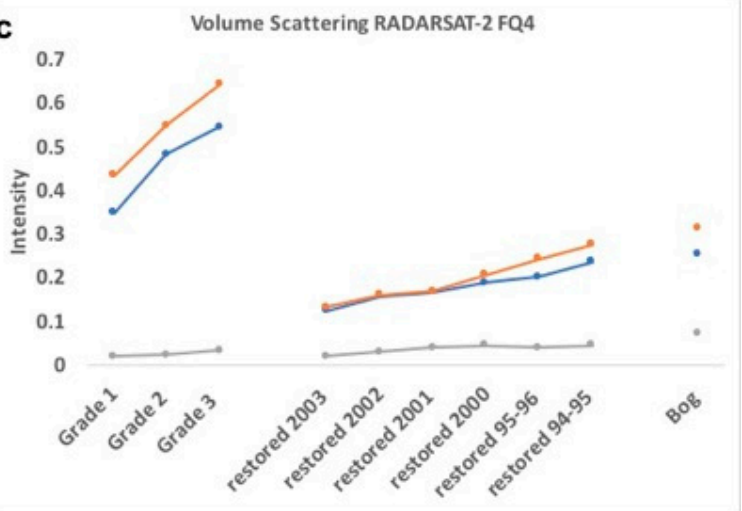

-15-Jul-15

22-Aug-15

-19-Oct-15

Figure 3. The Freeman-Durden decomposition spectral signatures for natural shrub bog, restored peat, and harvested peat using RADARSAT-2 FQ4 imagery. Double-bounce scattering is presented in (a), surface scattering in (b), and volume scattering in (c). All values are represented in decibels (dB). 
Table 5. The total power contributions from the Freeman-Durden decomposition. DB represents the percent of total power resulting from double-bounce backscatter, vol. the percent of total power from volume backscatter, and surf. the percent of total power from surface backscatter.

\begin{tabular}{|c|c|c|c|c|c|c|c|c|c|}
\hline \multirow[t]{2}{*}{ Peat State } & \multicolumn{3}{|c|}{ \% Total Power 15 July 2015} & \multicolumn{3}{|c|}{ \% Total Power 22 August 2015} & \multicolumn{3}{|c|}{ \% Total Power 19 October 2015} \\
\hline & $\%$ DB & \% Vol. & \% Surf. & $\%$ DB & $\%$ Vol. & \% Surf. & $\%$ DB & \% Vol. & $\%$ Surf. \\
\hline \multicolumn{10}{|c|}{ RADARSAT-2 FQ4 } \\
\hline Grade 1 & 2 & 29 & 70 & 2 & 36 & 62 & 2 & 18 & 81 \\
\hline Grade 2 & 2 & 38 & 60 & 2 & 34 & 64 & 2 & 16 & 83 \\
\hline Grade 3 & 2 & 39 & 60 & 2 & 31 & 67 & 2 & 19 & 79 \\
\hline Restored 2003 & 2 & 17 & 81 & 2 & 16 & 82 & 2 & 9 & 90 \\
\hline Restored 2002 & 3 & 28 & 69 & 3 & 31 & 66 & 2 & 16 & 83 \\
\hline Restored 2001 & 3 & 34 & 63 & 3 & 34 & 63 & 2 & 22 & 76 \\
\hline Restored 2000 & 3 & 32 & 65 & 3 & 35 & 62 & 1 & 22 & 77 \\
\hline Restored 1995-1996 & 3 & 39 & 58 & 3 & 42 & 55 & 1 & 19 & 79 \\
\hline Restored 1994-1995 & 4 & 48 & 49 & 3 & 48 & 49 & 2 & 24 & 74 \\
\hline Natural shrub bog & 5 & 63 & 31 & 4 & 69 & 27 & 3 & 40 & 57 \\
\hline \multicolumn{10}{|c|}{ RADARSAT-2 FQ26 } \\
\hline Grade 1 & 4 & 51 & 44 & 5 & 53 & 42 & 5 & 42 & 53 \\
\hline Grade 2 & 4 & 53 & 43 & 4 & 59 & 37 & 5 & 44 & 51 \\
\hline Grade 3 & 4 & 56 & 40 & 5 & 58 & 37 & 4 & 48 & 48 \\
\hline Restored 2003 & 4 & 48 & 47 & 6 & 45 & 50 & 4 & 38 & 59 \\
\hline Restored 2002 & 7 & 60 & 34 & 8 & 56 & 36 & 4 & 47 & 49 \\
\hline Restored 2001 & 8 & 65 & 27 & 8 & 66 & 27 & 5 & 57 & 39 \\
\hline Restored 2000 & 7 & 63 & 31 & 9 & 58 & 33 & 4 & 51 & 45 \\
\hline Restored 1995-1996 & 6 & 63 & 30 & 6 & 64 & 30 & 4 & 54 & 42 \\
\hline Restored 1994-1995 & 5 & 73 & 22 & 6 & 69 & 26 & 5 & 63 & 32 \\
\hline Natural shrub bog & 5 & 83 & 12 & 5 & 82 & 14 & 6 & 81 & 13 \\
\hline
\end{tabular}

Table 6. Total power contributions from the three types of scattering mechanisms in the Touzi incoherent target decomposition (ICTD). $\lambda_{1}$ is representative of the percentage of total power from rough surface backscattering, $\lambda_{2}$ from double-bounce backscattering, and $\lambda_{3}$ from volume backscattering.

\begin{tabular}{|c|c|c|c|c|c|c|c|c|c|}
\hline \multirow[t]{2}{*}{ Peat State } & \multicolumn{3}{|c|}{$\begin{array}{l}\text { \% Total Power } \\
15 \text { July } 2015\end{array}$} & \multicolumn{3}{|c|}{$\begin{array}{l}\% \text { Total Power } \\
22 \text { August } 2015\end{array}$} & \multicolumn{3}{|c|}{$\begin{array}{c}\text { \% Total Power } \\
19 \text { October } 2015\end{array}$} \\
\hline & $\% \lambda_{1}$ & $\% \lambda_{2}$ & $\% \lambda_{3}$ & $\% \lambda_{1}$ & $\% \lambda_{2}$ & $\% \lambda_{3}$ & $\% \lambda_{1}$ & $\% \lambda_{2}$ & $\% \lambda_{3}$ \\
\hline \multicolumn{10}{|c|}{ RADARSAT-2 FQ4 } \\
\hline Grade 1 & 86 & 9 & 5 & 83 & 11 & 6 & 90 & 6 & 3 \\
\hline Grade 2 & 82 & 12 & 6 & 84 & 11 & 5 & 92 & 6 & 3 \\
\hline Grade 3 & 82 & 12 & 6 & 85 & 10 & 5 & 90 & 7 & 3 \\
\hline Restored 2003 & 91 & 6 & 3 & 91 & 6 & 3 & 95 & 4 & 2 \\
\hline Restored 2002 & 84 & 11 & 5 & 83 & 12 & 5 & 92 & 6 & 3 \\
\hline Restored 2001 & 82 & 12 & 6 & 82 & 12 & 6 & 88 & 8 & 4 \\
\hline Restored 2000 & 83 & 11 & 5 & 82 & 12 & 6 & 89 & 7 & 3 \\
\hline Restored 1995-1996 & 80 & 14 & 6 & 79 & 14 & 7 & 90 & 6 & 3 \\
\hline Restored 1994-1995 & 76 & 16 & 8 & 77 & 16 & 8 & 88 & 8 & 4 \\
\hline \multirow[t]{3}{*}{ Natural shrub bog } & 68 & 22 & 11 & 67 & 22 & 11 & 88 & 8 & 4 \\
\hline & \multicolumn{3}{|c|}{$\begin{array}{l}\text { \% Total Power } \\
18 \text { July } 2015\end{array}$} & \multicolumn{3}{|c|}{$\begin{array}{r}\% \text { Total Power } \\
19 \text { August } 2015\end{array}$} & \multicolumn{3}{|c|}{$\begin{array}{c}\% \text { Total Power } \\
22 \text { October } 2015\end{array}$} \\
\hline & $\% \lambda_{1}$ & $\% \lambda_{2}$ & $\% \lambda_{3}$ & $\% \lambda_{1}$ & $\% \lambda_{2}$ & $\% \lambda_{3}$ & $\% \lambda_{1}$ & $\% \lambda_{2}$ & $\% \lambda_{3}$ \\
\hline \multicolumn{10}{|c|}{ RADARSAT-2 FQ26 } \\
\hline Grade 1 & 75 & 17 & 8 & 74 & 17 & 9 & 78 & 15 & 7 \\
\hline Grade 2 & 74 & 17 & 8 & 71 & 19 & 10 & 77 & 15 & 7 \\
\hline Grade 3 & 73 & 18 & 9 & 71 & 19 & 10 & 76 & 16 & 8 \\
\hline Restored 2003 & 75 & 17 & 8 & 76 & 17 & 8 & 94 & 20 & 9 \\
\hline Restored 2002 & 68 & 22 & 10 & 68 & 22 & 10 & 75 & 18 & 9 \\
\hline Restored 2001 & 65 & 24 & 12 & 65 & 23 & 11 & 71 & 20 & 9 \\
\hline Restored 2000 & 67 & 23 & 11 & 67 & 23 & 10 & 75 & 17 & 8 \\
\hline Restored 1995-1996 & 67 & 22 & 11 & 67 & 22 & 11 & 73 & 20 & 10 \\
\hline Restored 1994-1995 & 64 & 24 & 12 & 65 & 23 & 12 & 65 & 20 & 10 \\
\hline Natural shrub bog & 60 & 26 & 14 & 61 & 26 & 13 & 60 & 26 & 14 \\
\hline
\end{tabular}




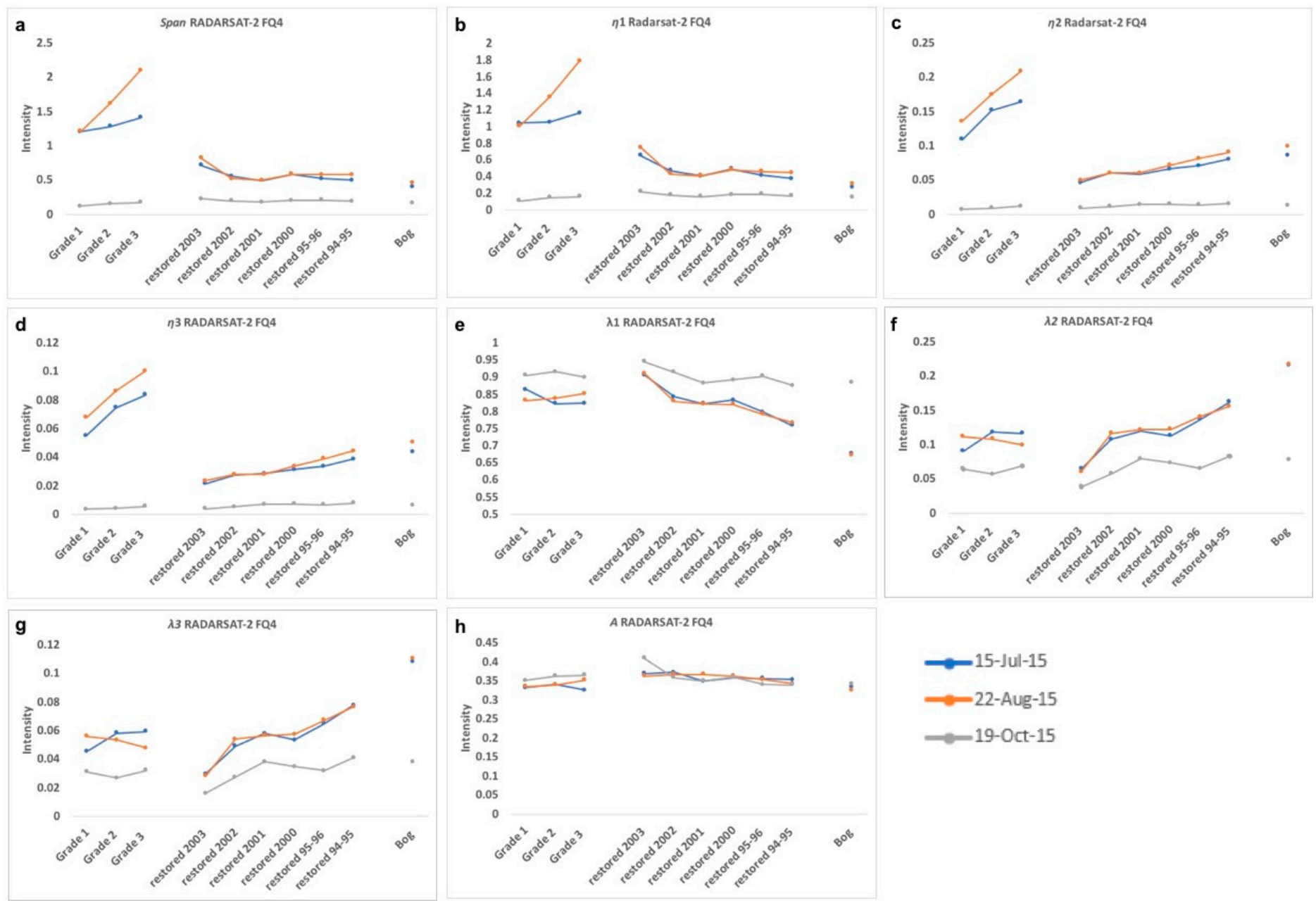

Figure 4. RADARSAT-2 FQ4 spectral signatures for natural shrub bog, restored peat, and actively harvested peat. (a) Total power (span), (b) dominant eigenvalue, (c) secondary eigenvalue, (d) tertiary eigenvalue, (e) normalized dominant eigenvalue, (f) normalized secondary eigenvalue, (g) normalized tertiary eigenvalue, and (h) anisotropy. 


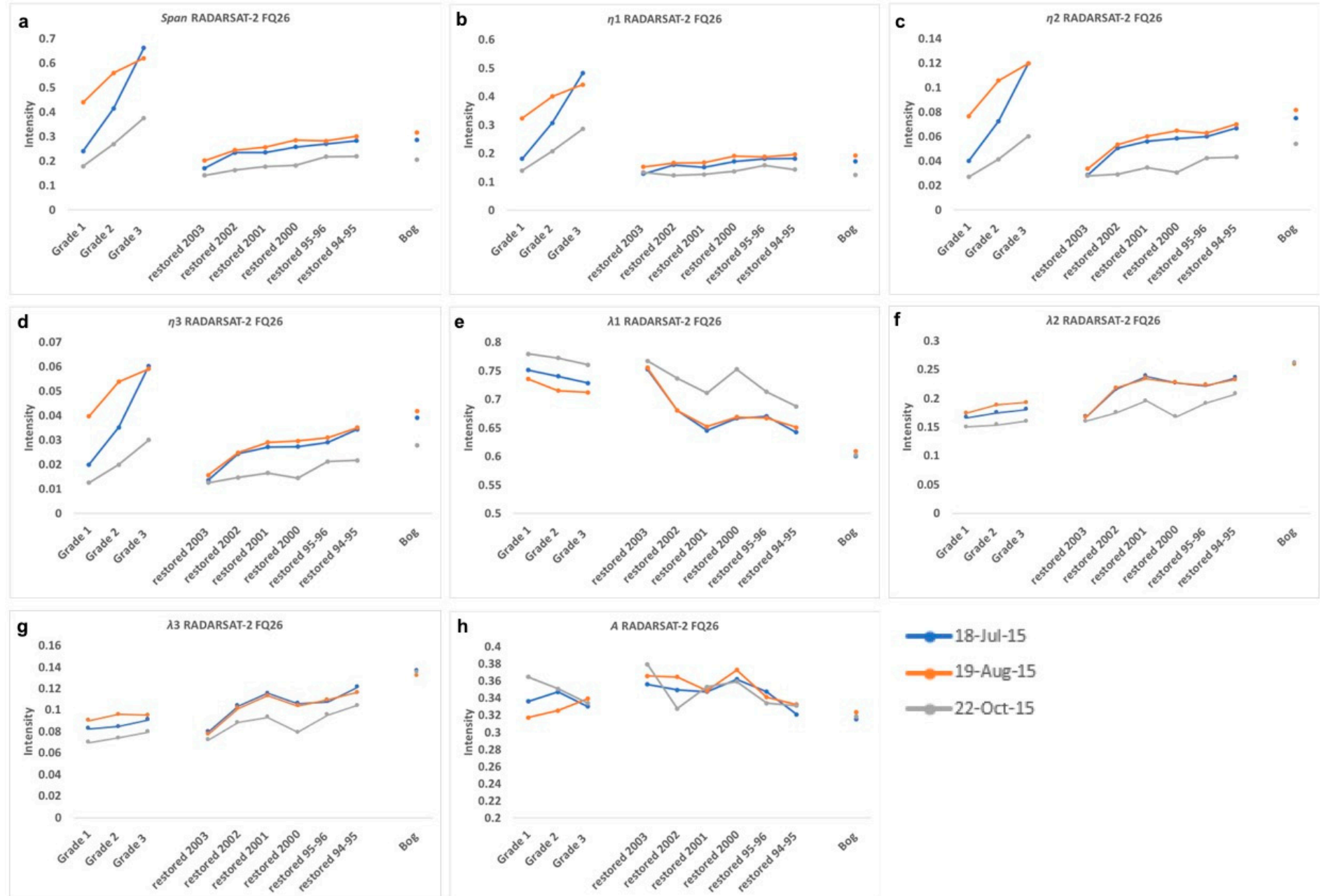

Figure 5. Spectral signatures for natural shrub bog, restored peat, and actively harvested peat using the RADARSAT-2 FQ26 images. (a) Total power (span), (b) dominant eigenvalue, (c) secondary eigenvalue, (d) tertiary eigenvalue, (e) normalized dominant eigenvalue, (f) normalized secondary eigenvalue, (g) normalized tertiary eigenvalue, and (h) anisotropy. 

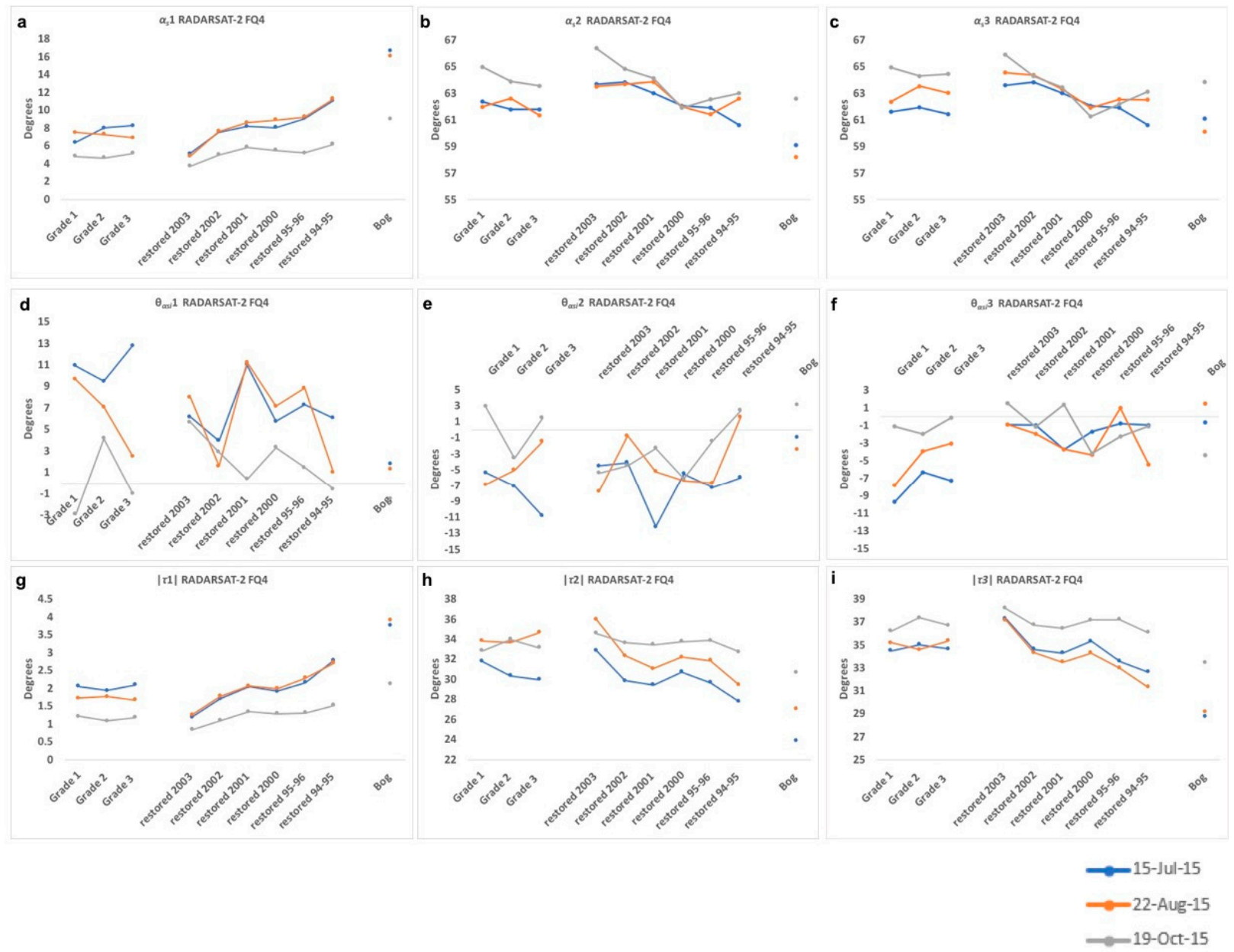

Figure 6. Spectral signatures for natural shrub bog, harvested peat, and restored peat using RADARSAT-2 FQ4 imagery. (a-c) Dominant, secondary, and tertiary scattering-type magnitude, (d-f) dominant, secondary, and tertiary scattering-type phase, and (g-i) dominant, secondary, and tertiary absolute value of helicity, respectively. 
3.2. Effect of Incidence Angle and Seasonal Timing on the Spectral Signatures of Restored Peat and Natural Shrub Bog

Differences in the rough surface and volume scattering were detected when both decompositions were applied to a fall RADARSAT-2 image or when a shallow incidence angle was used. We observed that for the October 19 FQ4 image $\alpha s_{1}$ remained more stable (Figure 6) and the $\lambda_{1}$ did not decline as much compared to the summer images (Table 6), indicating the magnitude in surface scattering did not decrease to the same degree the longer since peat was restored, which likely contributed to lower BD values. We also noticed a difference in the magnitude of rough surface and volume scattering when a shallow incidence angle was used. In the FD volume scattering accounted for a much larger portion of the total power in the FQ26 images compared to FQ4 images, resulting in the surface scattering being much less dominant (Figures 3 and 7, Table 6). The same observation was made in the ICTD, $\lambda_{1}$ was much lower in the FQ26 images (Figures 4 and 5). These results are further evidence that the incidence angle and timing of the growing season are important factors when trying to separate restored peat from natural shrub bog with RADSARSAT-2 imagery and suggest that a steeper incidence angle and peak vegetation conditions are preferred. 
a

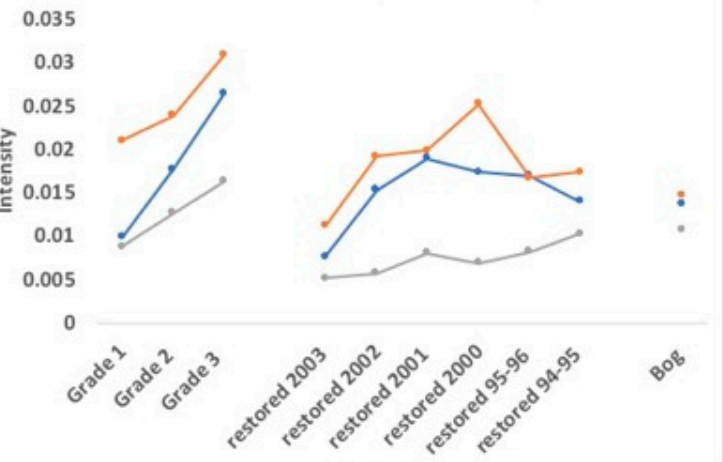

b

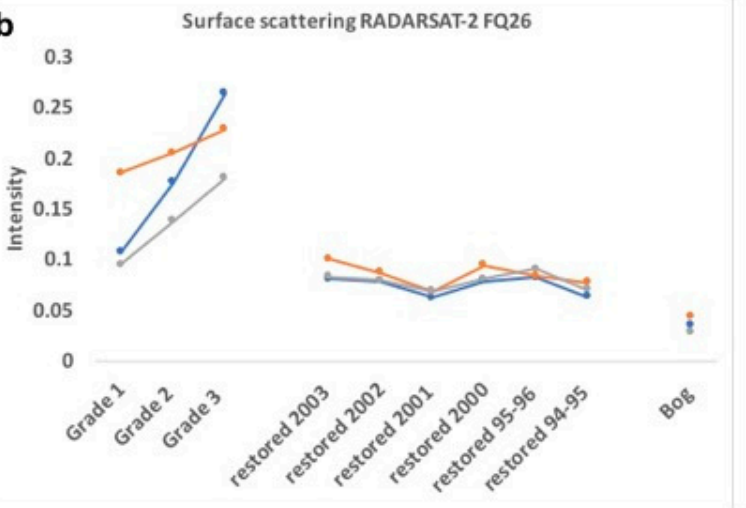

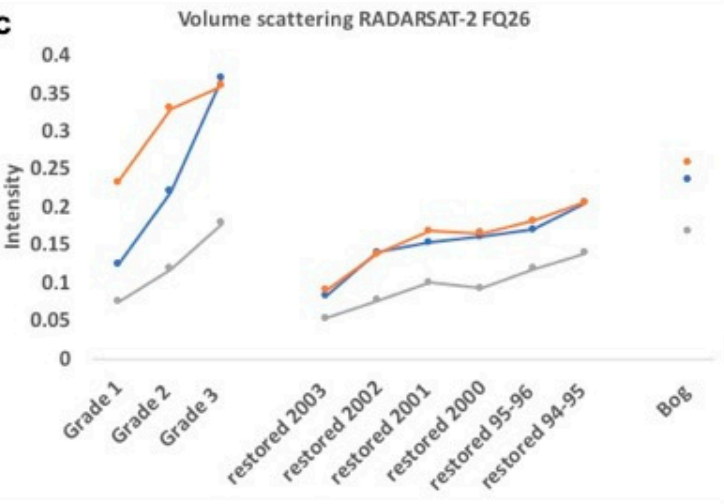

-18 -Jul-15

-19-Aug-15

$-22-$ Oct-15

Figure 7. Graphs show the spectral signatures of natural shrub bog, harvested peat, and restored peat when the Freeman-Durden decomposition was applied to RADARSAT-2 FQ26 images. Double-bounce scattering is presented in (a), surface scattering in (b), and volume scattering in (c). All values are represented in decibels $(\mathrm{dB})$. 
3.3. Contribution of the ICTD Parameters to the Separation of the Spectral Signatures of Restored Peat and Natural Shrub Bog

Helicity $\left|\tau_{1,2,3}\right|$ seems to be important for the spectral separation of restored peat from natural shrub bog. Values for $\left|\tau_{1}\right|$ are all $<4^{\circ}$ for peat restored from all years, as well as natural shrub bog, indicating the dominant rough surface scattering was symmetric (Figure 8). Therefore, most of the restored peat had a smooth surface, resulting in specular reflection and a symmetric angle to the radar incidence angle. Peat restored in 2003 had $\left|\tau_{1}\right|$ values closest to $0^{\circ}$, with values slowly increasing to $\sim 4-5^{\circ}$ for peat restored in 1994-1995, becoming closer to the $\left|\tau_{1}\right|$ values of natural shrub bog $\left(\sim 5-6^{\circ}\right)$, (Figure 8$)$. This is consistent with the same trend we saw earlier with the backscatter response of restored peat becoming more similar to natural shrub bog the longer since peat was restored. When $\left|\tau_{2,3}\right|$ was examined all values $>22^{\circ}$ (Figure 8 ), suggesting the secondary and tertiary scattering mechanisms, were asymmetric. $\left|\tau_{3}\right|$ values generally declined the longer since peat was restored (Figure 8) and became closer to $\left|\tau_{3}\right|$ observed in natural shrub bog. As the vegetation grew and the surface of the restored peat became more symmetric, the angle to the radar incidence angle became less asymmetric. This additional information from the ICTD $|\tau|$ parameter describing the symmetry of the ground targets is likely contributing to the ability of the ICTD to better separate the spectral signatures of restored peat and natural shrub bog compared to the FD decomposition which does not have helicity as a parameter.

Examination of the anisotropy values suggests that restored peat and natural shrub bog are not characterized by more than one scattering mechanism. All anisotropy values over-restored peat and natural shrub bog were $<0.5$ indicating that the second and third scattering mechanisms are fairly mixed, and the third eigenvalue is not important. Thus, although we observed volume scattering increasing slightly over time in restored peat and becoming more similar to values observed in natural shrub bog, it does not appear that volume or double-bounce scattering is important for the separation of restored peat and natural shrub bog.

The $\theta$ s parameter did not seem to be useful for separating the spectral signatures of restored peat and natural shrub bog. For both the FQ4 and FQ26 incidence angles there was no real trend of increasing or decreasing $\theta \mathrm{s}$ the longer since peat was restored (Figures 7 and 8 ). This may be due to the lack of ideal conditions needed for phase coherence. Natural shrub bog did not have phase coherence for either a steep or shallow incidence angle for all three months $\left(\mathrm{P}_{\Phi \alpha}<0.8\right.$, Table A1). There were some cases where restored peat did have phase coherence $\left(\mathrm{P}_{\Phi \alpha}>0.8\right)$, for example, peat restored in 2003 and all restored peat in October (Table A1). However, this did not appear to improve the ability to separate restored peat from natural shrub bog. 


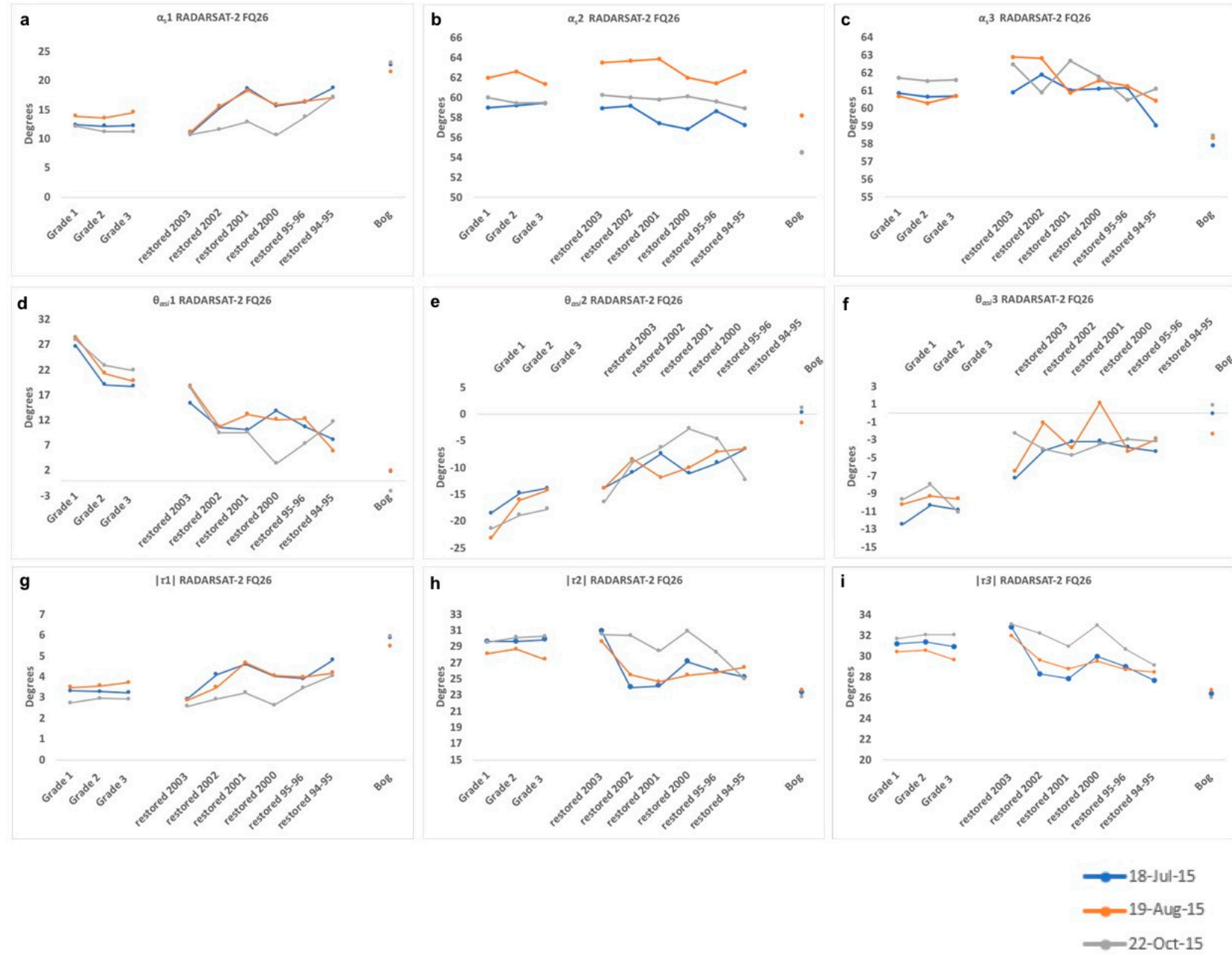

Figure 8. Graphs show the spectral signatures for natural shrub bog, harvested peat, and restored peat derived from RADARSAT-2 FQ26 imagery. (a-c) Dominant, secondary, and tertiary scattering-type magnitude, $(\mathbf{d}-\mathbf{f})$ dominant, secondary, and tertiary scattering-type phase, and (g-i) dominant, secondary, and tertiary absolute value of helicity, respectively. 


\subsection{Comparison of the Spectral Signatures of Harvested Peat to Natural Shrub Bog}

The spectral separability analysis in this research also demonstrates that peat that is being actively harvested can in some cases be spectrally separated from natural shrub bog. The ICTD was able to separate the spectral signatures of all three grades of harvested peat from natural shrub bog using the FQ4 July 15, RADARSAT-2 image (BD >= 1.9, Table 2). The ability of the ICTD to separate harvested peat from natural shrub bog with a steep incidence angle decreased slightly as the timing of the growing season progressed. For example, in the FQ4 August 22 image the ICTD could only separate grades 2 and 3 from natural shrub bog, and grades 1 and 2 in the FQ4 October 19 image. The difference between the secondary and tertiary $|\tau|$ values for harvested peat and natural shrub bog was $\sim 2.4-5.8^{\circ}$ less in October compared to July. The volume and double-bounce scattering in the natural shrub bog were becoming more asymmetric as the growing season progressed, making it more difficult to separate their spectral signatures from harvested peat. When a shallow incidence angle (FQ26) was used, the ICTD could not separate any grade of harvested peat from natural shrub bog (Tables 2-4). We compared the values for the $\alpha_{1}$ and $\lambda_{1}$ for the FQ4 and FQ26 RADARSAT-2 images, and the FQ4 $\alpha_{1}$ values were closer to $0^{\circ}$, and the magnitude of the $\lambda_{1}$ was $\sim 8-10 \%$ higher for harvested peat and natural shrub bog. Thus, being able to detect a stronger surface scattering response with a steep incidence angle in both the harvested peat and natural shrub bog, likely improved the ability to separate the spectral signatures of these classes, coupled with a larger difference in the symmetry of double-bounce and volume scattering earlier in the growing season.

The FD was unable to separate any grade of harvested peat from natural shrub bog for both the steep and shallow incidence angles for any of the months included in this analysis $(\mathrm{BD}<0.9$, Tables $2-4)$. One difference between the ICTD and FD we observed was the magnitude of the dominant backscatter type. In the ICTD the $\lambda_{1}$ indicated that the dominant backscatterer was rough surface scattering for both natural shrub bog and harvested peat, and accounted for the majority of the magnitude for total power. For instance, when looking at the FQ4 images, the $\lambda_{1}$ showed that for natural shrub bog, rough surface scattering accounted for $\sim 68-88 \%$ of the total power and $\sim 82-92 \%$ for harvested peat (Table 6 ). Conversely, for natural shrub bog the dominant backscattering mechanism in the FD differed and did not account for as large a portion of the total power. For the same FQ4 images volume scattering was considered to be the dominant backscatterer for natural shrub bog and only accounted for $~ 40-63 \%$ of the total power, while rough surface scattering was $\sim 27-57 \%$ of the total power (Table 5). Similarly, when we compared the $\mathrm{dB}$ values of ICTD $\eta_{1}$ and the FD rough surface scattering, the $\eta_{1} \mathrm{~dB}$ values were $~ 0.25-3.0 \mathrm{~dB}$ higher for the FQ4 images and $\sim 0.2-9.9 \mathrm{~dB}$ higher in the FQ26 images (Figure 9). This is further evidence that the magnitude of the rough surface scattering in the ICTD was stronger compared to the FD. For harvested peat, the FD agreed with the ICTD that rough surface scattering was the dominant scattering mechanism, but only contributed $\sim 60-83 \%$ to the total power, which was $\sim 10-20 \%$ less compared to the ICTD (Tables 5 and 6 ). When we compared the HV intensity, FD volume scattering, and ICTD $\eta_{3}$ the FD volume scattering was $~ 7-10 \mathrm{~dB}$ higher than both the HV intensity and ICTD $\eta_{3}$ for both the FQ4 and FQ26 RADARSAT-2 images (Figure 10). The higher dB values and percentage of total power for the FD volume scattering may be affecting the separability of the spectral signatures for the harvested peat and natural shrub bog classes. 


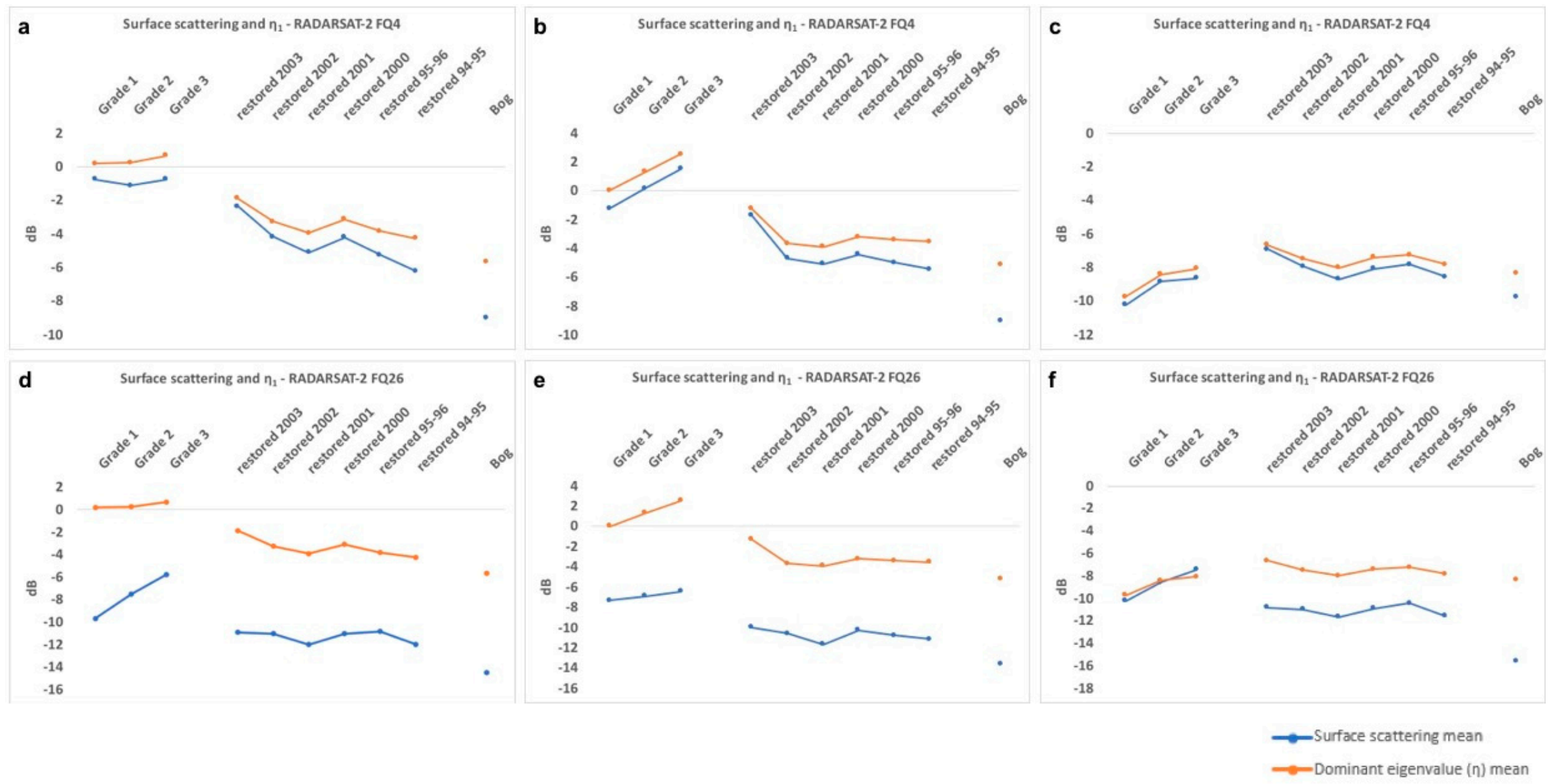

Figure 9. Comparison of $\mathrm{dB}$ values from the FD rough surface scattering and the ICTD $\eta_{1}$ for July $15 \mathrm{FQ} 4$ (a), August 22 FQ4 (b), October 19 FQ4 (c), July 18 FQ26 (d), August 15 FQ26 (e), and October 22 FQ26 (f) 2015 RADARSAT-2 images. 


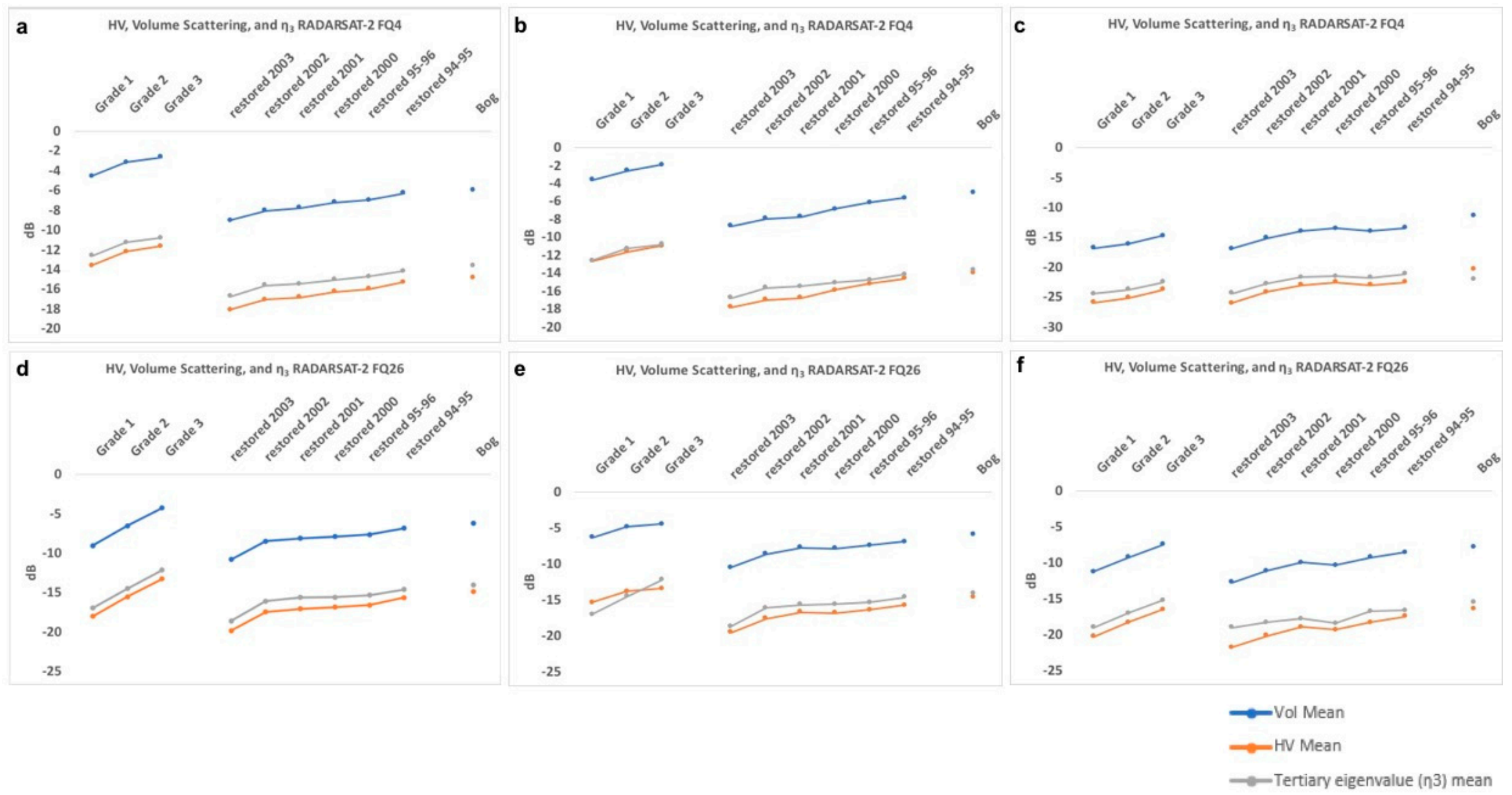

Figure 10. Comparison of dB values from HV intensity, the FD volume scattering, and the ICTD $\eta_{3}$ for July 15 FQ4 (a), August 22 FQ4 (b), October 19 FQ4 (c), July 18 FQ26 (d), August 15 FQ26 (e, October 22 FQ26 (f) 2015 RADARSAT-2 images. 


\subsection{Comparison of the Spectral Signatures of Harvested Peat and Restored Peat}

Both the ICTD and FD had some success is separating the spectral signatures of peat being actively harvested and restored peat. Like in many of the previous examples, the ICTD outperformed the FD. The ICTD was able to separate grade 3 harvested peat from restored peat in 2000-2003 for both the July and August FQ4 images (Tables 2 and 3). The $\alpha_{3}$, which is representative of volume scattering was slightly higher $\left(\sim 2-3^{\circ}\right.$, Figure 7$)$ for peat restored more recently (2000-2003), indicating that volume scattering gradually increased the longer since peat was restored. The difference between $\alpha_{3}$ values for grade 3 harvest peat and earlier restored peat was greatest in July and August (peak growing season), which may have resulted in higher BD values. We observed a similar pattern in the volume scattering from the FD decomposition. The largest difference in $\mathrm{dB}$ was between grade 3 harvested peat and peat restored in 2003 for both steep and shallow incidence angles (Figures 3 and 4). Volume scattering increased as the grade of harvested peat increased, and the longer since the peat was restored, resulting in peat restored in 1994-1995 having volume scattering values most similar to grade 3 harvested peat, thus making them more difficult to separate. When a shallow incidence angle was used, the ICTD could only separate grade 3 harvested peat and peat restored in 2000-2003 in July and 2003 in August (Tables 2 and 3). The FD was able to successfully separate the spectral signatures of grade 3 harvested peat from restored peat 2003 in July with both the steep and shallow incidence angles, grade 3 from peat harvested in 2001-2003 in August with a steep incidence angle, and grade 3 harvested peat from peat restored in August, 2003 with a shallow incidence angle (Tables 2 and 3). Although the degree of coherence was highest for restored peat and harvested peat in October this did not improve the ability to separate the two classes. These results suggest that peak growing season conditions, and steep incidence angle and the ICTD are best able to separate the spectral signatures of harvested peat and restored peat.

\subsection{Manual Visual Interpretation of UAS Imagery}

Manual interpretation of the UAS imagery was challenging in part due to the nature of the onboard camera system and the auto-exposure control. There were considerable changes in lighting throughout the two-day period due to sun angle and the presence of clouds. As a result of the exposure issues, colour was not found to be a very useful image feature in the discrimination of areas of predominately Polytrichum versus Sphagnum (Figure 11). In addition to difficulties related to the colour and exposer efforts to mosaic and georeference photos were challenging due to difficulty in obtaining a sufficient number of accurate ground tie points in the very homogenous site landscape. Despite these challenges, it was found that manual interpretation using feature texture and pattern was somewhat successful in determining discriminating Polytrichum from Sphagnum moss-covered areas (Figure 11). From ground-based observations we observed restored areas with successfully established Sphagnum in the UAS imagery to have a much higher number of woody shrubs compared to Polytrichum predominate cover areas. Polytrichum covered areas had a smoother texture indicating low vegetation cover (moss, herbs, grasses). Areas of natural bog were observed to have a high degree of woody shrub and low tree secondary canopy cover. Areas of active peat harvest or recent abandonment or restoration were observed to be generally smooth in texture. 

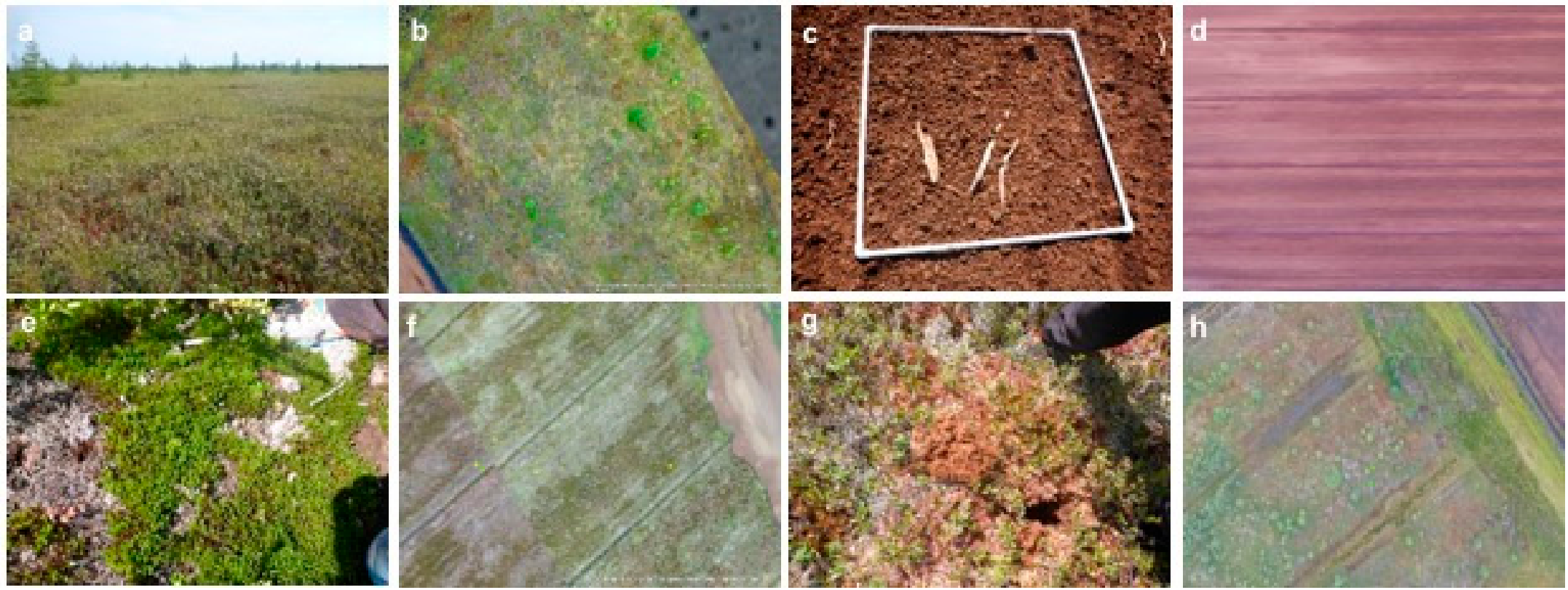

Figure 11. Sainte-Marguerite-Marie peatland field site photos and UAS imagery. Photos (a) representative natural bog, (b) UAS imagery for the natural bog, (c) exposed peat layer prepared for harvest, (d) UAS imagery for harvest area, (e) post-restoration area with Polytrichum cover, (f) UAS imagery for Polytrichum covered area, (g) Predominantly Sphagnum moss-covered site, and (h) UAS imagery for a Sphagnum covered area. 


\section{Discussion}

\subsection{Polarimetric Decompositions}

Results from this analysis suggest that the longer since peat is restored the more similar its spectral response resembles that of natural shrub bog, which can be detected by both the FD and the ICTD. A similar result was found when manually interpreting the UAS imagery. These results are not surprising, because when peat is first restored it will mainly consist of mosses like Sphagnum and Polytrichum, as well as areas of bare soil, resulting in a strong rough surface backscatter to the satellite. Similar results were observed by [70], who concluded that rough surface scattering had the strongest backscatter return to the SAR system for areas with Sphagnum mosses, really low shrub vegetation and microtopography within the Alfred Bog peatland complex. We observed the growth of shrubs (Chamaedaphne calyculata, Rhododendron groenlandicum, Andromeda polifolia), herbs (Sarracenia purpurea, Eriophorum angustifolium) and trees (Larix laricina, Betula papyrifera) for areas of peat that had been restored for several years, which was consistent with the vegetation observed in the natural shrub bog, and resulted in higher volume scattering. It is expected to detect some volume scattering in peatlands because the vegetation consists of many small scatters (leaves, branches, etc.) that cause the emitted SAR energy to be returned in multiple directions [27]; however, shrub or treed bog will have higher volume scattering compared to open bog [70].

The ICTD was better at distinguishing the differences in the spectral signatures of the restored peat and natural shrub bog, and actively harvested peat from restored peat (Bhattacharya values $>=1.9$ ), which may result in better classification accuracies compared to the FD. The rough surface scattering accounted for a larger portion of the total power in the ICTD compared to the FD for harvested peat and peat recently restored. The difference in the magnitude of rough surface scattering and volume scattering was less in the FD, and therefore there was more mixing between the two scattering mechanisms, making the spectral signatures of restored peat, harvested peat, and natural shrub bog more difficult to separate. This was likely due to the two known limitations with the FD, the first being that the received direct scattering component should start at the ground surface level. However, in the FD decomposition, some of this scattering can come from above ground vegetation because the canopy of the vegetation can also cause scattering with similar polarimetric features [71,72]. The second issue is that the FD assumes a Bragg model for ground surfaces, and thus cannot model the cross-polar backscattering in instances when the ground is really rough. This results in the cross-polar signal being identified as volume scattering [71,72]. Both of these limitations can result in the proportion volume scattering being overestimated, which was observed in this study and contributed to lower spectral separability success. When trying to separate spectral surfaces or classify SAR imagery in areas with dominant surface scattering such as peatlands the ICTD would be the recommended decomposition.

Additionally, the information provided by the helicity parameter in the ICTD likely contributed to the ICTD being better able to separate the spectral signatures of natural shrub bog, restored peat, and harvested peat. Values for both $\left|\tau_{1}\right|$ and $\left|\tau_{3}\right|$ became closer to those observed in natural shrub bog the longer the duration for which the peat had been restored. The surface scattering $\left|\tau_{1}\right|$ became slightly more asymmetric over time, while the volume scattering $\left|\tau_{3}\right|$ became somewhat more symmetric. Restored peat in the earlier years had less vegetation and was dominated by surface scattering resulting in mostly symmetric scattering. As vegetation starts to grow and volume scattering increases, it causes $\left|\tau_{1}\right|$ to be more asymmetric.

We did not find the $\Phi$ as to be an important ICTD parameter for spectral separation of natural shrub bog, restored peat, and actively harvested peat using C-band RADARSAT-2. This is in contrast to other studies conducted with the C-band Convair-580 SAR and L-band ALOS imagery, both which have shown the $\Phi$ as to be able to detect sub-surface water, allowing for the separation of dry and wet peatland conditions $[46,63,73]$. To exploit the information provided by $\Phi$ as for peatland scattering characterization, very accurate measurements of HV during the quad-pol measurement has to be conducted. This permits the characterization of peatland subsurface hydrology with enough coherent 
phase. Such conditions can be easily satisfied with the longer wavelength $(23 \mathrm{~cm})$ found on the ALOS L-band satellite, because it allows for deeper penetration into the ground surface, and also has an excellent noise equivalent sigma naught (NESZ about -34 dB). It is harder to achieve with SAR satellites that have a shorter wavelength, such as the C-band of RADARSAT-2 despite the comparable NESZ of the C-band satellite SAR ( -34dB). Touzi et al. [74] compared ALOS-2 to RADARSAT-2 in Wapsuk National Park to determine if wavelength affected the discrimination of bog and fen. Results from this study demonstrated that the longer wavelength from the ALOS-2 imagery was able to penetrate below the peat, allowing for the detection of subsurface water flow and separate bog from fen. Most of the restored peat and natural shrub bog in this study was not coherent in the summer months. Although restored peat, harvested peat, and natural shrub bog were coherent in the October FQ4 image, we still did not detect a trend in the phase that would improve class separation.

\subsection{Noise Equivalent Sigma Naught}

It is important to note that in order to accurately measure HV in quad-pol measurements a low NESZ is also necessary. Such characterization could be reached with the airborne Convair-580 SAR C-band airborne system, which had a NESZ better than $-48 \mathrm{~dB}$, as demonstrated and discussed in $[46,63,73]$. Touzi et al. [46] compared the Convair-580 SAR C-band airborne system and RADARSAT-2 in the Mer Bleue wetland complex. The noise floor on the Convair-580 SAR is - 48 dB [72] in comparison to $-34 \mathrm{~dB}$ for RADARSAT-2 [74]. The authors of [46] demonstrated that the detection of sub-surface water level resulting in bog fen separation was promising with the Convair-580 SAR but not with RADARSAT-2. Touzi et al. concluded that the higher NESZ in RADARSAT-2 is responsible for the lack of detection of sub-surface water [74]. The resolution of the CV580 in the slant range is about $5 \mathrm{~m}$ in range and $40 \mathrm{~cm}$ in azimuth. At about a 40-degree incidence angle, the ground range resolution is about $5 / \sin (40)=7 \mathrm{~m}$ ground range resolution [75]. Future work will investigate whether SAR satellite systems with a longer wavelength such as ALOS or the upcoming NISAR (expected to be launched in 2022) will improve the separation of restored peat from actively harvested peat and natural shrub bog. The inability for RADARSAT- 2 to detect coherent targets and sub-surface water was likely a result of the combination of the wavelength and NESZ.

\subsection{Incidence Angle}

Incidence angle strongly influenced the ability of RADARSAT-2 to be able to separate the spectral signatures of restored peat from natural shrub bog, restored peat from harvested peat, and harvested peat from natural shrub bog. In all cases, a steep incidence angle (FQ4) resulted in higher BD values $(>=1.9)$. These results are consistent with other research which showed steeper incidence angles improve the detection of bogs because there is less canopy interference, causing more surface scattering [76], and have been shown to be better for separating or classifying different classes of wetlands [77,78]. Li et al. [79] concluded that a steeper incidence angle was preferred for peatland mapping after demonstrating that C-Band RADARSAT- 1 was only able to penetrate short (0.2-0.4 m), shrubby vegetation with steep incidence angles. Therefore, we recommend a steep incidence angle when mapping or monitoring peatland restoration with SAR imagery.

\subsection{Timing of the Growing Season}

The timing of the growing season also influenced the spectral separability of the peat classes in this study but to a lesser degree. The ICTD was best able to differentiate restored peat from harvested peat (BD values $\geq 1.9$ ) when a steep incidence angle (FQ4) was used in July or August. When separating the spectral signatures of harvested peat from restored peat the ICTD had the highest BD values in August, while the July image appeared to best be able to separate natural shrub bog from harvested peat. In all cases, the mid to peak growing season yields the best separability for the peat class spectral signatures. This is likely because during this time frame volume scattering will also be at its peak, thus aiding in the separability of the peat classes. 


\subsection{Unammed Aerial Systems}

The challenges we encountered with using the UAS imagery to identify Sphagnum and Polytrichum were in part due to study design. We did not manually add any GCPs throughout the study area. Additional GCPs would have improved the accuracy of the mosaic and orthorectification and enabled easier interpretation of the images and comparison to field observations and [11]. Without the correct number of GCPs, we were not able to produce high-precision image mosaics by orthorectification using the Pix4D software or ArcGIS. There was a shift on the order of 10-20 m when we compared the UAS mosaics to other sources of ancillary data which made it challenging to cross-validate with our field observations of Sphagnham and Polytrichum. Many patches of Sphagnham and Polytrichum were quite small (less than $25 \mathrm{~cm}^{2}$ ), so even small shifts in alignment made it difficult to compare with the UAS imagery. Thus, the analysis had to be done using georeferenced and rectified individual photos which made image processing and interpretation more challenging and time consuming.

We also did not use colour infrared (CIR) imagery. Other studies have successfully used CIR UAS imagery to map and monitor vegetation [80-83] (because the differences in reflectance between plant species is most easily seen in the near-infrared portion of the electromagnetic spectrum [84]. The authors of $[55,81]$ used CIR in combination with object-based classification to monitor peat bogs. It is likely we would have had better success in using colour to separate Sphagnum and Polytrichum had we included the near-infrared band in our UAS flights. However, despite these challenges, we were able to achieve some success in identifying and separating Sphagnum and Polytrichum in the UAS imagery. We believe these initial results show promise for using UAS imagery as a first step to determine the early success of peatland restoration. Future research will focus on incorporating manual GCP's, applying correct radiometric and colour corrections, using CIR imagery, and investigating the possibility of classifying Sphagnum and Polytrichum.

\section{Conclusions}

Results from this research suggest that the ICTD, steep incidence angle and mid to peak growing season are the optimal parameters for spectral separability (BD values $\geq 0.9$ ) of restored peat from natural shrub bog and peat being actively harvested. Analysis of the spectral signatures showed that the longer since peat was restored the more similar its spectral signature became to natural shrub bog (BD values declining the longer since peat was restored). The additional information provided by the helicity ICTD parameter about the symmetrical nature of the ground features appeared to provide additional information that improved spectral separability and was not included in the FD. Additionally, our analysis suggested the FD was overestimating volume scattering, which may have contributed to higher spectral confusion between restored peat, natural shrub bog, and actively harvested peat. A UAS with a high-quality camera system and a good set of ground observations and control points could prove to be a useful aid in the assessment of restoration conditions and act as an additional tool in collecting ground reference for further radar analysis.

While this research indicates that applying the ICTD to RADARSAT-2 imagery and UASs could be used as tools to monitor the success of restored peat there were limitations in the study design. Future work will address these limitations by:

(1) Applying the methodology to a larger study site with more training and validation data to allow for image classification and more detailed analysis.

(2) Using L-band SAR imagery to determine whether a longer wavelength would allow for the exploitation of the $\Phi a s$ ICTD parameter, and in turn, result in better spectral separation of restored peat from natural shrub bog and actively harvested peat.

(3) Adding additional GPS points to improve UAS image orthorectification and mosaicking.

(4) Fly the UAS under similar lighting conditions to reduce auto exposure and improve the identification of Sphagnum and Polytrichum. 
Author Contributions: Conceptualization, L.W., M.M., S.H., R.T., J.P. and J.D.; Methodology, L.W., M.M., S.H., R.T., J.P. and J.D; Software, L.W. and M.M.; Validation, L.W., M.M., S.H., R.T., J.P. and J.D.; Formal Analysis, L.W., M.M., S.H., R.T., J.P. and J.D.; Investigation, L.W. and M.M.; Data curation, L.W., M.M.; Writing-Original Draft Preparation, L.W; Writing-Review and Editing, L.W., M.M., S.H., R.T., J.P. and J.D.; Visualization, L.W. and M.M; Project administration, L.W. All authors have read and agreed to the published version of the manuscript.

Funding: This research received no external funding.

Acknowledgments: The authors would like to thank the Fafard Restoration company for providing access to the restored peatland area and for sharing their knowledge of the peatland harvesting and restoration process. We thank the reviewers for their helpful comments and suggestions. The authors also thank Tom Giles, and Matt Giles for organizing and planning the UAS flights. RADARSAT-2 Data and Products (C) Maxar Technologies Ltd. (2018) - All Rights Reserved. RADARSAT is an official mark of the Canadian Space Agency.

Conflicts of Interest: The authors declare no conflict of interest

\section{Appendix A}

Table A1. Degree of Coherence.

\begin{tabular}{ccccccc}
\hline Peat State & \multicolumn{3}{c}{ RADARSAT-2 FQ4 } & \multicolumn{2}{c}{ RADARSAT-2 FQ26 } \\
\hline & 15 July 2015 & 22 August 2015 & 19 October 2015 & 18 July 2015 & 19 August 2015 & 22 October 2015 \\
\hline Grade 1 & 0.79 & 0.80 & 0.88 & 0.68 & 0.65 & 0.70 \\
Grade 2 & 0.79 & 0.80 & 0.89 & 0.66 & 0.63 & 0.61 \\
Grade 3 & 0.82 & 0.82 & 0.87 & 0.65 & 0.66 \\
Restored 2003 & 0.81 & 0.88 & 0.93 & 0.67 & 0.54 & 0.69 \\
Restored 2002 & 0.71 & 0.77 & 0.89 & 0.55 & 0.50 \\
Restored 2001 & 0.80 & 0.75 & 0.85 & 0.48 & 0.69 \\
Restored 2000 & 0.78 & 0.76 & 0.86 & 0.53 & 0.61 \\
Restored 1995-1996 & 0.67 & 0.73 & 0.87 & 0.53 & 0.65 \\
Restored 1994-1995 & 0.73 & 0.68 & 0.83 & 0.51 & 0.53 \\
Natural shrub bog & 0.53 & 0.56 & 0.75 & 0.46 & 0.47 \\
\hline
\end{tabular}

\section{References}

1. Preliminary Estimate of the Mineral Production of Canada, by Province. 2017. Available online: https: //sead.nrcan--rncan.gc.ca/prod--prod/Prelim--data--en.aspx?FileT=1\&FileYr=2017\&Lang=en (accessed on 19 October 2016).

2. Price, J.S. Hydrology and microclimate of a partly restored cutover bog, Quebec. Hydrol. Process. 1996, 10, 1263-1272. [CrossRef]

3. Waddington, J.M.; Rotenberg, P.A.; Warren, F.J. Peat CO2 production in a natural and cutover peatland: Implications for restoration. Biogeochemistry 2001, 54, 115-130. [CrossRef]

4. Climate Change 2013 The Physical Science Basis. 2013. Available online: http://www.climatechange2013.org/ images/report/WG1AR5_ALL_FINAL.pdf (accessed on 18 October 2016).

5. Rochefort, L.; Quinty, F.; Campeua, S.; Johnson, L.; Malterer, T. North American approach to the restoration of Sphagnum dominated peatlands. Wetl. Ecol. Manag. 2003, 11, 3-20. [CrossRef]

6. Gorham, E.; Rochefort, L. Peatland Restoration: A brief assessment with special reference to Sphagnum bogs. Wetl. Ecol. Manag. 2003, 11, 109-119. [CrossRef]

7. Price, J.S.; Rochefort, L.; Quinty, F. Energy and moisture considerations on cutover peatlands: Surface microtopography, mulch cover and Sphagnum regeneration. Ecol. Eng. 1998, 10, 293-312. [CrossRef]

8. Poulin, P.L.; Rochefort, F.; Quinty, C. Lavoie. Spontaneous revegetation of mined peatlands in eastern Canada. Can. J. Bot. 2005, 83, 539-557. [CrossRef]

9. Chirino, C.; Campeau, S.; Rochefort, L. Sphagnum establishment on bare peat: The importance of climatic variability and Sphagnum species richness. Appl. Veg. Sci. 2006, 9, 285-294. [CrossRef]

10. Groeneveld, E.V.G.; Massé, A.; Rochefort, L. Polytrichum strictum as a nurse-plant in peatland restoration. Restor. Ecol. 2007, 15, 709-719. [CrossRef]

11. González, E.; Rochefort, L.; Boudreau, S.; Poulin, M. Combining indicator species and key environmental and management factors to predict restoration success of degraded ecosystems. Ecol. Indic. 2014, 46, 156-166. [CrossRef] 
12. Hobbs, R.J. The future of restoration ecology: Challenges and opportunities. Restor. Ecol. 2005, 3, $239-241$. [CrossRef]

13. Wohl, E.; Angermeier, P.L.; Bledsoe, B.; Kondolf, G.M.; MacDonnell, L.; Merritt, D.M.; Palmer, M.A.; Poff, N.L.; Tarboton, D. River restoration. Water Resour. Res. 2005, 41, W10301. [CrossRef]

14. Bernhardt, E.S.; Sudduth, E.B.; Palmer, M.A.; Allan, J.D.; Meyer, J.L.; Alexander, G.; Follstad Shah, J.; Hassett, B.; Jenkinson, R.; Lave, R.; et al. Restoring rivers one reach at a time: Results from a survey of U.S. river restoration practitioners. Restor. Ecol. 2007, 15, 482-493. [CrossRef]

15. Rochefort, L. New frontiers in bryology and lichenology-Sphagnum-A keystone genus in habitat restoration. Bryologist 2000, 103, 503-508. [CrossRef]

16. Herrick, J.; Schumand, G.E.; Rango, A. Monitoring ecological processes for restoration projects. J. Nat. Conserv. 2006, 14, 161-171. [CrossRef]

17. Palylyk, C.L.; Crown, P.H.; Turchenek, L.W. Landsat MSS Data for Peatland Inventory in Alberta; Rubec, C.D.A., Overend, R.P., Eds.; Canadian Society of Wetlands and Peatlands and Canadian National Committee, International Peat Society: Edmonton, AB, Canada, 1987; pp. 365-367.

18. Touzi, R.; Deschamps, A.; Rother, G. Wetland characterization using polarimetric Radarsat-2 capability. Can. J. Remote Sens. 2007, 33, S56-S67. [CrossRef]

19. Li, J.; Chen, W. A rule-based method for mapping Canada's wetlands using optical, radar and DEM data. Int. J. Remote Sens. 2005, 26, 5051-5069. [CrossRef]

20. Touzi, R.; Omari, K.; Sleep, B.; Jiao, X. Scattered and received wave polarization optimization for enhanced peatland classification and fire damage assessment using polarimetric PALSAR. IEEE J. Sel. Topics Appl. Earth Obs. Remote Sens. 2018, 11, 4452-4477. [CrossRef]

21. Smith, L.C. Satellite remote sensing of river inundation area, stage, and discharge: A review. Hydrol. Process 1997, 11, 1427-1439. [CrossRef]

22. Campbell, J.B. Introduction to Remote Sensing, 3rd ed.; The Guilford Press: New York, NY, USA, 2002; pp. 1-621.

23. Töyrä, J.; Pietroniro, A. Towards operational monitoring of a northern wetland using geomatics-based techniques. Remote Sens. Environ. 2005, 97, 174-191. [CrossRef]

24. Bourgeau-Chavez, L.L.; Riordan, K.; Powell, R.B.; Miller, N.; Nowels, M. Improving wetland characterization with multi-sensor, multi-temporal SAR and optical/infrared data fusion. In Advances in Geoscience and Remote Sensing; INTECH: Rijeka, Croatia, 2009.

25. Baghdadi, N.; Bernier, M.; Gauthier, R.; Neeson, I. Evaluation of C-band SAR data for wetlands mapping. Int. J. Remote Sens. 2001, 22, 71-88. [CrossRef]

26. Townsend, P.A. Relationships between forest structure and the detection of flood inundation in forested wetlands using C-band SAR. Int. J. Remote Sens. 2002, 23, 443-460. [CrossRef]

27. Henderson, F.M.; Lewis, A.J. Principles and Applications of Imaging Radar-Manual of Remote Sensing; Wiley: Hoboken, NJ, USA, 1998.

28. Jin, Y.-Q.; Xu, F. Polarimetric Scattering and SAR Information Retrieval; Wiley: Hoboken, NJ, USA, 2013; pp. 1-27.

29. Kaojarern, S.; Le Toan, T.; Davidson, M.W.J. Monitoring surface soil moisture in post harvest rice areas using C-band radar imagery in northeast Thailand. Geocarto Int. 2004, 19, 61-70. [CrossRef]

30. Boerner, W.M.; Mott, H.; Luneburg, E.; Livingstone, C.; Brisco, B.; Brown, R.J.; Paterson, J.S.; Cloude, S.R.; Krogager, E.; Lee, J.S.; et al. Polarimetry in radar remote sensing: Basic and applied concepts. In Manual of Remote Sensing: Principles and Applications of Imaging Radar, 2nd ed.; Henderson, F.M., Lewis, A.J., Eds.; Wiley: Hoboken, NJ, USA, 1998; pp. 271-356.

31. Touzi, R.; Boerner, W.M.; Lee, J.S.; Luneberg, E. A review of polarimetry in the context of synthetic aperture radar: Concepts and information extraction. Can. J. Remote Sens. 2004, 30, 380-407. [CrossRef]

32. Brisco, B.; Kapfer, M.; Hirose, T.; Tedford, B.; Liu, J. Evaluation of C-band polarization diversity and polarimetry for wetland mapping. Can. J. Remote Sens. 2011, 37, 82-92. [CrossRef]

33. Flett, D.; Crevier, Y.; Girard, R. The RADARSAT Constellation Mission: Meeting the government of Canada's needs and requirements. In Proceedings of the 2009 IEEE International Geoscience and Remote Sensing Symposium, Cape Town, South Africa, 12-17 July 2009; pp. 907-910.

34. Lee, J.-S.; Pottier, E. Polarimetric Radar Imaging-From Basics to Applications; CRC Press, Taylor \& Francis Group: Boca Raton, FL, USA, 2009.

35. Van Zyl, J.J.; Kim, Y.J. Synthetic Aperture Radar Polarimetry; Wiley: New York, NY, USA, 2011. 
36. White, L.; Brisco, B.; Dabboor, M.; Schmitt, A.; Pratt, A. A collection of SAR methodologies for monitoring wetlands. Remote Sens. 2015, 7, 7615-7645. [CrossRef]

37. De Almeida Furtado, L.F.; Silva, T.S.F.; de Moraes Novo, E.M.L. Dual-season and full-polarimetric C band SAR assessment for vegetation mapping in the Amazon várzea wetlands. Remote Sens. Environ. 2016, 174, 212-222. [CrossRef]

38. Amani, M.; Salehi, B.; Mahdavi, S.; Brisco, B. Separability analysis of wetlands in Canada using multi-source SAR Data. GISci. Remote Sensing. 2019, 56, 1233-1260. [CrossRef]

39. Brisco, B.; Touzi, R.; van der Sanden, J.J.; Charbonneau, F.; Pultz, T.; D’Iorio, M. Water resource applications with RADARSAT-2-A preview. Int. J. Digit. Earth 2008, 1, 130-147. [CrossRef]

40. Hess, L.; Melack, J.; Novo, E.; Barbosa, C.; Gastil, M. Dual season mapping of wetland inundation and vegetation for the central Amazon Basin. Remote Sens. Environ. 2003, 87, 404-428. [CrossRef]

41. Lane, C.R.; D'Amico, E. Calculating the ecosystem service of water storage in isolated wetlands using LiDAR in North Central Florida, United States. Wetlands 2010, 30, 967-977. [CrossRef]

42. Brisco, B.; Li, K.; Tedford, B.; Charbonneau, F.; Yun, S.; Murnaghan, K. Compact polarimetry assessment for rice and wetland mapping. Int. J. Remote Sens. 2013, 34, 1949-1964. [CrossRef]

43. Wdowinski, S.; Kim, S.W.; Amelung, F.; Dixon, T.H.; Miralles-Wilhelm, F.; Sonenshein, R. Space-based detection of wetlands' surface water level changes from L band SAR interferometry. Remote Sens Environ. 2008, 112, 681-696. [CrossRef]

44. Freeman, A.; Durden, S.L. A three-component scattering model for polarimetric SAR data. IEEE Trans. Geosci. Remote Sens. 1998, 36, 963-973. [CrossRef]

45. Touzi, R. Target scattering decomposition in terms of roll invariant target parameters. IEEE Trans. Geosci. Remote Sens. 2007, 45, 73-84. [CrossRef]

46. Touzi, R.; Deschamps, A.; Rother, R. Phase of target scattering for wetland characterization using polarimetric C-band SAR. IEEE TGRS 2009, 47, 3241-3261. [CrossRef]

47. Huynen, J. Measurement of the target scattering matrix. Proc. IEEE 1965, 53, 936-946. [CrossRef]

48. Touzi, R.; Bhattacharya, A.; Mattar, K. Multi-resolution target scattering decomposition for urban feature characterization using polarimetric SAR. Proc. Int. Geosci. Remote Sens. Symp. 2009, 4, IV-857-IV-860.

49. Cloude, S. The Characterization of Polarization Effect in EM Scattering. Ph.D. Thesis, Faculty of Eng., Univ. Birmingham, Birmingham, UK, 1986.

50. Ulaby, F.T.; EL-Rayes, M.A. Microwave dielectric spectrum of vegetation. Part II, Dual disperson model. IEEE Trans. Geosci. Remote Sens. 1987, 25, 550-557. [CrossRef]

51. Corr, D.; Rodrigues, A. Alternative basis matrices for polarimetric decomposition. In Proceedings of the EUSAR, Cologne, Germany, 4-6 June 2002; VDE-Verl: Berlin, Germany, 2002.

52. Lee, J.; Schuler, D.; Ainsworth, T. Polarimetric SAR data compensation for terrain azimuth slope variation. IEEE Trans. Geosci. Remote Sens. 2000, 38, 2153-2163.

53. Touzi, R. Polarimetric target scattering decomposition: A review. In Proceedings of the 2016 IEEE International Geoscience and Remote Sensing Symposium (IGARSS), Beijing, China, 10-15 July 2016; pp. 5658-5661.

54. Lehmann, J.R.K.; Nieberding, F.; Prinz, T.; Knoth, C. Analysis of Unmanned Aerial System-Based CIR Images in Forestry-A New Perspective to Monitor Pest Infestation Levels. Forests 2015, 6, 594-612. [CrossRef]

55. Knoth, C.; Klein, B.; Prinz, T.; Kleinebecker, T. Unmanned aerial vehicles as innovative remote sensing platforms for high-resolution infrared imagery to support restoration monitoring in cut over bogs. Appl. Veg. Sci. 2013, 16, 509-517. [CrossRef]

56. Lucieer, A.; Turner, D.; King, D.H.; Robinson, S.A. Using an Unmanned Aerial Vehicle (UAV) to capture micro-topography of Antarctic moss beds. Int. J. Appl. Earth Obs. Geoinf. 2014, 27, 53-62. [CrossRef]

57. Kalacska, M.; Arroyo-Mora, J.P.; de Gea, J.; Snirer, E.; Herzog, C.; Moore, T.R. Videographic analysis of eriophorum vaginatum spatial coverage in an ombotrophic bog. Remote Sens. 2013, 5, 6501-6512. [CrossRef]

58. Quinty, F.; Rochefort, L. Peatland Restoration Guide, 2nd ed.; Canadian Sphagnum Peat Moss Association and New Brunswick Depearment of Natural Resources and Energy: Quebec City, QC, Canada, 2003; pp. 1-106.

59. Rochefort, L.; Lode, E. Restoration of degraded boreal peatlands. In Boreal Peatland Ecosystems; Wieder, R.K., Vitt, D.H., Eds.; Springer-Verlag: Berlin, Germany, 2006; pp. 381-423.

60. Graf, M.; Bérubé, V.; Rochefort, L. Restoration of peatlands after peat extraction. In Restoration and Reclamation of Boreal Ecosystems; Vitt, D., Bhatti, J., Eds.; Cambridge University Press: Cambridge, UK, 2012; pp. 259-280. 
61. Raney, R.K. The Delay/Doppler Radar Altimeter. IEEE Trans. Geosci. Remote Sens. 1998, 36, 1578-1588. [CrossRef]

62. Touzi, R.; Gosselin, G.; Brook, R. Polarimetric L-band SAR for peatland mapping and monitoring. In ESA Book on Principles and Applications of Pol-InSAR; Springer: New York, NY, USA, 2018.

63. Touzi, R. Speckle effect on polarimetric target scattering decomposition of SAR imagery. Can. J. Remote Sens. 2007, 33, 60-68. [CrossRef]

64. Touzi, R.; Charbonneau, F. Characterization of target symmetric scattering using polarimetric SARs. IEEE Trans. Geosci. Remote Sens. 2002, 40, 2507-2516. [CrossRef]

65. Born, M.; Wolf, E. Principles of Optics: Electromagnetic Theory of Propagation, Interference and Diffraction of Light, 7th ed.; Cambridge University Press: Elmsford, NY, USA, 1999; pp. 1-985.

66. About Parameters and Discriminators. Available online: http://www.pcigeomatics.com/geomatica--help/ concepts/spw_c/spw3N128.html (accessed on 7 July 2016).

67. Bhattacharyya, A. On a measure of divergence between two statistical populations defined by their probability distribution. Bull. Calcutta Math. Soc. 1943, 35, 99-110.

68. Landgrebe, D. Information extraction principles and methods for multispectral and hyperspectral image data. Inf. Process. Remote Sens. 1999, 82, 3-38.

69. Chang, C.I.; Du, Q.; Sun, T.; Althouse, M.L.G. A joint band prioritization and band decorrelation approach to band selection for hyperspectral image classification. IEEE Trans. Geosci. Remote Sens. 1999, 37, 2631-2641. [CrossRef]

70. Millard, K. Development of methods to map and monitor peatland ecosystems and hydrologic conditions using Radarsat-2 Synthetic Aperture Radar. Ph.D. Thesis, Carleton University, Ottawa, ON, Canada, 2016.

71. Hajnsek, I.; Jagdhuber, T.; Schön, H.; Papathanassiou, K.P. Potential of estimating soil moisture under vegetation cover by means of PolSAR. IEEE Trans. Geosci. Remote Sens. 2009, 47, 442-454. [CrossRef]

72. Ballester-Berman, J.D.; Lopez-Sanchez, J.M. Applying the Freeman-Durden Decomposition Concept to Polarimetric SAR Interferometry. IEEE Trans. Geosci. Remote Sens. 2010, 48, 466-479. [CrossRef]

73. Touzi, T.; Gosselin, G. Peatland subsurface water flow monitoring using polarimetric L-band PALSAR. In Proceedings of the IEEE International Geoscience \& Remote Sensing Symposium, IGARSS 2010, Honolulu, HI, USA, 25-30 July 2010.

74. Touzi, R.; Omari, K.; Gosselin, G.; Sleep, B. Polarimetric L-band ALOS for peatland subsurface water monitoring. In Proceedings of the 2013 Asia-Pacific Conference on Synthetic Aperture Radar (APSAR), Tsukuba, Japan, 23-27 September 2013; pp. 53-56.

75. Livingstone, C.E.; Gray, A.L.; Hawkins, R.K.; Vachon, P.W.; Lukowski, T.I.; LaLonde, M. The CCRS airborne SAR systems: Radar for remote sensing research. Can. J. Remote Sens. 1995, 21, 468-491. [CrossRef]

76. Merchant, M. Examining the Influence of Subarctic Boreal Ground Conditions on C-Band Radarst-2 Polsar Variables for Target Separability and the Application of a Support Vector Machine Classifier. Master's Thesis, University of Guelph, Guelph, ON, Canada, 2014.

77. Bourgeau-Chavez, L.L.; Kasischke, E.S.; Brunzell, S.M.; Mudd, J.P.; Smith, K.B.; Frick, A.L. Analysis of space-borne SAR data for wetland mapping in Virginia riparian ecosystems. Int. J. Remote Sens. 2001, 22, 3665-3687. [CrossRef]

78. Dingle-Robertson, L.; King, D.J.; Davies, C. Object-based image analysis of optical and radar variables for wetland evaluation. Int. J. Remote Sens. 2015, 36, 5811-5841. [CrossRef]

79. Li, X.; Gar-On Yeh, A.; Wang, S.; Liu, K.; Liu, X.; Qian, J.; Chen, X. Regression and Analytical Models for Estimating Mangrove Wetland Biomass in South China Using Radarsat Images. Int. J. Remote Sens. 2007, 28, 5567-5582. [CrossRef]

80. Zarco-Tejada, P.J.; Diaz-Varela, R.; Angileri, V.; Loudjani, P. Tree height quantification using high resolution imagery acquired from an unmanned aerial vehicle (UAV) and automatic 3D photo-reconstruction methods. Eur. J. Agron. 2014, 55, 89-99. [CrossRef]

81. Lehmann, J.R.K.; Münchberger, W.; Knoth, C.; Blodau, C.; Nieberding, F.; Prinz, T.; Pancotto, V.; Kleinebecker, T. High-Resolution Classification of South Patagonian Peat Bog Microforms Reveals Potential Gaps in Up-Scared CH4 Fluxes by use of Unmanned Aerial System (UAS) and CIR Imagery. Remote Sens. 2016, 8, 173. [CrossRef]

82. Pietsch, M.; Henning, M.; Mader, D.; Westfeld, P.; Etterer, F. Using Unmanned Aerial Vehicles (UAV) for Monitroing Biodiversity Measure in Periurban and Agrarian Landscapes. J. Digital Landsc. Archit. 2018, 3, 273-282. 
83. Klouček, T.; Komárek, J.; Surový, P.; Hrach, K.; Janata, P.; Vašíček, B. The Use of UAV Mounted Sensors for Precise Detection of Bark Beetle Infestation. Remote Sens. 2019, 11, 1561. [CrossRef]

84. Ihse, M. Colour infrared aerial photography as a tool for vegetation mapping and change detection in environmental studies of Nordic ecosystems: A Review. Nor. Geogr. Tidsskr. 2007, 61, 170-191. [CrossRef]

(C) 2020 by the authors. Licensee MDPI, Basel, Switzerland. This article is an open access article distributed under the terms and conditions of the Creative Commons Attribution (CC BY) license (http://creativecommons.org/licenses/by/4.0/). 